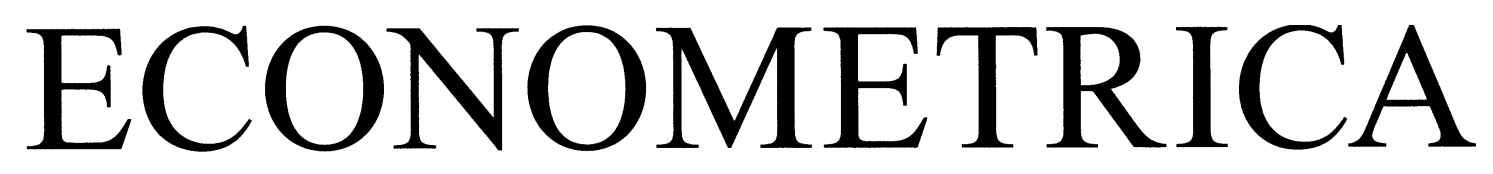

JOURNAL OF THE ECONOMETRIC SOCIETY

An International Society for the Advancement of Economic Theory in its Relation to Statistics and Mathematics

http://www.econometricsociety.org/

Econometrica, Vol. 84, No. 4 (July, 2016), 1477-1521

\title{
WHY DOESN'T TECHNOLOGY FLOW FROM RICH TO POOR COUNTRIES?
}

\author{
HAROLD L. COLE \\ University of Pennsylvania, Philadelphia, PA 19104-6297, U.S.A. \\ JEREMY GREENWOOD \\ University of Pennsylvania, Philadelphia, PA 19104-6297, U.S.A. \\ JUAN M. SANCHEZ \\ Federal Reserve Bank of St. Louis, St. Louis, MO 63166-0442, U.S.A.
}

The copyright to this Article is held by the Econometric Society. It may be downloaded, printed and reproduced only for educational or research purposes, including use in course packs. No downloading or copying may be done for any commercial purpose without the explicit permission of the Econometric Society. For such commercial purposes contact the Office of the Econometric Society (contact information may be found at the website http://www.econometricsociety.org or in the back cover of Econometrica). This statement must be included on all copies of this Article that are made available electronically or in any other format. 


\title{
WHY DOESN'T TECHNOLOGY FLOW FROM RICH TO POOR COUNTRIES?
}

\begin{abstract}
By Harold L. Cole, Jeremy GreEnwood, And JuAn M. SANCheZ ${ }^{1}$
What is the role of a country's financial system in determining technology adoption? To examine this, a dynamic contract model is embedded into a general equilibrium setting with competitive intermediation. The terms of finance are dictated by an intermediary's ability to monitor and control a firm's cash flow, in conjunction with the structure of the technology that the firm adopts. It is not always profitable to finance promising technologies. A quantitative illustration is presented where financial frictions induce entrepreneurs in India and Mexico to adopt less-promising ventures than in the United States, despite lower input prices.
\end{abstract}

KEYWORDS: Costly cash-flow control, costly state verification, dynamic contract theory, economic development, establishment-size distributions, finance and development, financial intermediation, India, Mexico, and the United States, monitoring, productivity, retained earnings, self-finance, technology adoption, ventures.

\section{INTRODUCTION}

WHY DO COUNTRIES USE DIFFERENT PRODUCTION TECHNOLOGIES? Surely, all nations should adopt best-practice technologies, which produce the highest levels of income. Yet, this does not happen. To paraphrase Lucas (1990): Why doesn't technology flow from rich to poor countries? The question is even more biting when one recognizes that poor countries often have much lower factor prices than rich ones. Hence, any technology that is profitable to run in a rich country should be even more profitable to run in a poor one. The premise here is that the efficiency of financial markets plays a vital role in technology adoption. In particular, when financial markets are inefficient, it may not be profitable to borrow the funds to implement certain types of technologies, even when factor prices are very low. If a country's financial markets affect its technology adoption, then it is a small step to argue that they will affect the nation's total factor productivity (TFP) and income.

\subsection{The Theoretical Analysis}

A dynamic costly state verification model of venture capital is developed. The model has multiple unique features. First, production technologies are represented in a more general way than in the usual finance and development literature. Entrepreneurs start new firms every period. There is a menu of potential technologies that can be operated. Entrepreneurs can select and operate a single blueprint from this menu of technologies. A firm's blueprint is represented by a non-decreasing stochastic process that describes movement

\footnotetext{
${ }^{1}$ The authors thank two referees for their comments.
} 
up a productivity ladder. Some blueprints have productivity profiles that offer exciting profit opportunities; others are more mundane. This is operationalized by assuming there are differences in the positions of the rungs on the productivity ladders, as well as in the odds of climbing up the rungs. Blueprints also differ in the required capital investment. Some may require substantial investment before much information about the likely outcome is known. The structure of a technology ladder is very important. It interacts with the efficiency of a financial system in a fundamental way to determine whether it is profitable to finance a project and, if so, the terms of a lending contract.

A start-up firm will ask an intermediary to underwrite its venture. The financial contract between the new firm and the intermediary is long term in duration, unlike most of the literature, which assumes short-term contracts. Short-term contracts may lie inside the Pareto frontier characterizing the payoffs for the borrower and lender. Therefore, it may be possible that a technology that cannot be financed with a short-term contract, because it entails a loss for one of the parties, can still be financed with a long-term one. A contract specifies a state-contingent plan over the life cycle of the project, outlining the advancement of funds from the intermediary to the firm and the payments from the firm back to the intermediary. A firm's position on a productivity ladder is private information. Since the flow of funds depends on reports by the firm to the intermediary, there is an incentive for the firm to misrepresent its position to the intermediary. Intermediaries can audit the returns of a firm, as in the prototypical costly state verification paradigms of Townsend (1979) and Williamson (1986).

A distinguishing feature of the contracting framework is that the intermediary can pick the odds of a successful audit. The cost of auditing is increasing and convex in these odds. This cost is also decreasing in the productivity of a country's financial sector. Another unique feature of the analysis is the notion of poor cash-flow control. Specifically, it is assumed that some fraction of a firm's cash flow can never be secured by the intermediary via contractual means due to a poor rule of law in a country. The analysis allows for a new firm to self-finance some of the start-up costs of the venture at the time of writing a contract. The contract also specifies the amount of self-financing of inputs that the firm undertakes over time using the cash that flows into retained earnings.

Several propositions are proved. It is established that, in general, the intermediary pays the firm its rewards only if it reaches the top of the productivity ladder (modulo any payments it has to make due to poor cash-flow control). Additionally, when the firm has an incentive to lie, the intermediary will audit all reports of a failure to move up the ladder. Auditing reduces the incentive to deceive. When there is poor cash-flow control, the intermediary will also have to provide rewards even when the firm fails to move up the ladder. This reduces its ability to backload. The nature of the blueprint, a country's input prices, and the state of its financial system will determine the profitability of a project. For certain blueprints, it may not be feasible for an intermediary to 
offer a lending contract that will make the project profitable. This situation can arise because given the structure of the technology ladder: (i) input prices are too high, (ii) the level of monitoring needed to make the project viable is simply too expensive given the efficiency of the financial system, or (iii) poor cash-flow control makes it impossible to implement enough backloading. Thus, the state of a nation's financial system will have an impact on the type of ventures that will be financed. Financial sector efficiency will affect a nation's income and TFP. Therefore, a link between finance and development is established.

\subsection{The Quantitative Illustration}

A quantitative illustration of the theory developed here is provided. The purpose is twofold. First, it establishes the potential of the financial mechanism developed here to explain cross-country differences in incomes and TFPs. On this, the quantitative illustration is not intended as a formal empirical assessment of the theory outlined here or as a means to discriminate between this and other financial mechanisms. ${ }^{2}$ Second, the quantitative illustration elucidates some of the theoretical mechanisms at play: (i) the interplay between the efficiency of a financial system and technology adoption, (ii) the role of monitoring, and (iii) the relationship between backloading, retained earnings, and internal (self-) financing of investment.

Motivated by Hsieh and Klenow (2014), the applied analysis focuses on three countries at very different levels of development: India, Mexico, and the United States. There are some interesting differences in establishments across these three countries. Average establishment size is much smaller in Mexico than in the United States and is much smaller in India than in Mexico. (These facts are presented later in Table III, Section 9.) This may be due to the fact that TFP is higher in a U.S. plant than in a Mexican one, which in turn is higher than in an Indian establishment. The share of employment contributed by younger (older) establishments is also much larger (smaller) in India and Mexico than in the United States. On this, TFP in a U.S. establishment increases much faster with age than in a Mexican one, which rises more quickly than in an Indian plant. These facts suggest that these countries are using very different technologies.

To undertake the quantitative illustration, a stylized version of the model is used where there are only three production technologies available: advanced, intermediate, and entry level. A firm in India, Mexico, and the United States

\footnotetext{
${ }^{2}$ For example, Buera, Kaboski, and Shin (2011) and Midrigan and Xu (2014) focused on the importance of borrowing constraints. Limited investor protection was emphasized by Antunes, Cavalcanti, and Villamil (2008) and Castro, Clementi, and MacDonald (2004). Greenwood, Sanchez, and Wang (2013) applied the static contract model of Greenwood, Sanchez, and Wang (2010) to the international data. The role of financial intermediaries in producing ex ante information about investment projects was stressed by Townsend and Ueda's (2010) work on Thailand.
} 
is free to pick the technology that it desires. Each project has a different blueprint. The structure of a technology plays an important role in the quantitative illustration. The advanced technology promises high returns. When the project successfully climbs all of the rungs of the productivity ladder, the time path of TFP has a very convex shape. This implies that growth in employment, output, and profits materialize toward the end of the project's life cycle. The project requires large up-front investment. The entry-level technology has a lower expected return. Employment, output, and profits follow a concave time path when the project scales the ladder triumphantly. The project's returns are therefore more immediate. It requires less start-up investment. The intermediate technology lies between these two. To impose some discipline on the analysis, the model's general equilibrium is constructed so that factor prices match those in India, Mexico, and the United States. Labor is much less expensive in India than in Mexico, which in turn is less expensive than in the United States. Thus, on first appearance, the advanced technology should be more profitable in India than in Mexico, and more profitable in Mexico than in the United States.

Some questions arise: Can an equilibrium be constructed where the United States will use the first technology, Mexico the second, and India the third? Can such a structure match the above stylized facts about the Indian, Mexican, and U.S. economies, including the observations on establishment-size distributions? Does financial development matter for economic development? The answers to these three questions are yes. Differences in financial development play an important role in economic development. They explain a significant portion of the differences in cross-country incomes, but primarily through the technology adoption channel and not through capital deepening (or misallocation, which is not touched on in the current analysis). Still, they do not explain the majority of the differences in incomes among India, Mexico, and the United States.

The quantitative analysis is also used to highlight some key points in the theoretical analysis. In particular, it is shown explicitly how the pattern of technology adoption is a function of monitoring efficiency and the extent of the cash-flow control problem. The advanced and intermediate technologies cannot be implemented when monitoring is not efficient and/or when there is a significant cash-flow problem. Additionally, it is illustrated that given the structure of the entry-level technology, it can be financed quickly using the flow of cash into retained earnings. This is not the case for the advanced technology, which requires significant amounts of external financing throughout the life of the project. The fact that the evolution of retained earnings depends on the technology being financed has implications for a country's private-debtto-GDP ratio. The framework predicts that the ratio of private debt to GDP will rise with GDP. Why is this important? The observed concordance of this ratio with GDP is often interpreted as indicating that firms in poor countries rely more on internal funds (either start-up funds or through retained earnings) than those in rich nations. The current analysis suggests that this arises, 
in part, because of differences across countries in the pattern of cash flow into retained earnings related to variations in the patterns of technology adoption. These differences in technology adoption arise, to some extent, from variations in financial structures.

\subsection{Finance and Development: A Brief Literature Review}

Earlier work has drawn a connection between finance and the adoption of technologies. For example, Greenwood and Jovanovic (1990) allowed for two technologies: a primitive one with a low, certain rate of return and an advanced one with a higher expected, but uncertain rate of return. By pooling risks, intermediaries reduce the vagaries associated with the advanced technology. There are fixed costs associated with intermediation, so only the wealthy choose to use this channel. Banerjee and Duflo (2005) presented a stylized model where more advanced technologies require larger investments in terms of fixed costs. Given the presence of borrowing constraints, countries such as India lack the wherewithal to finance advanced technologies. They suggested this as a potential explanation for the productivity gap between India and the United States.

Within the context of a two-sector model where technologies may differ, Buera, Kaboski, and Shin (2011) quantitatively examined the link between financial development and economic development. They emphasized the importance of borrowing and enforcement constraints. Greenwood, Sanchez, and Wang $(2010,2013)$ allowed for an infinite number of technologies. Better intermediation prunes the ones with low returns from the economy. In all of these papers, technologies differ in a simple way. The prototypical setting is similar to Greenwood and Jovanovic (1990): Better technologies have higher expected levels of productivity, are riskier, and usually involve a higher fixed cost in terms of adoption.

The decision to finance a venture is likely to depend on the nature of the technology in a more deep-rooted manner. Selling drinks on the street is much different than launching rockets into space. The former requires a small investment that yields returns relatively quickly and with little risk. The latter requires years of funding before any returns are realized and there is tremendous risk associated with financing such ventures. To capture this notion, technologies are given a much richer representation than is conventionally assumed.

Why is this important? The structure of the technology adopted and the efficiency of the financial system are likely to be inextricably linked. Consider a model where entrepreneurs are constrained by some initial level of wealth and can borrow only a limited amount per period on short-term markets. Intuitively, one would expect a firm to be much more capable of self-financing a project over time if the profile for TFP is flat, implying a flat profile of capital, as opposed to one where productivity perpetually grows in a convex manner requiring ever-increasing levels of investments. Midrigan and Xu (2014) argued that with stationary AR(1)-style productivity shocks (in logs), the capital required by a firm can be accumulated reasonably quickly by self-financing (see 
also Moll (2014) for an analysis of how the degree of persistence in technology shocks and the ability to self-finance interact). ${ }^{3}$

In an extension, Midrigan and Xu (2014) concluded that the impact of intermediation on technology adoption is more important than its impact on the allocation of capital across plants for explaining TFP. They did this in a setting where the technology in a modern sector can be upgraded once, with complete certainty, at a fixed cost. This rules out technologies of the type considered here with convex productivity profiles where the high returns are skewed toward the end of the firm's life cycle and occur with low probability. ${ }^{4}$ Additionally, the focus of their analysis was on a single country, South Korea. Hence, they did not ask how technology adoption is interconnected with cross-country differences in factor prices and financial systems. The fact that factor prices are much lower in countries such as India is an important consideration when modeling crosscountry technology adoption. Doing this in general equilibrium while matching cross-country differences in factor prices and firm-size distributions, as is done here, is not an easy task. Finally, given that the main focus of their paper was on the impact of finance on the misallocation of capital, and not technology adoption, Midrigan and $\mathrm{Xu}$ (2014) did not try to match their extension with facts about the firm-size distribution. ${ }^{5}$

The analysis here uses dynamic contracts, as opposed to the use of shortterm contracts in the bulk of the literature. Short-term contracts leave money on the table. They do not allow lenders to commit to extended punishment strategies, such as withholding future funds based on a bad report or auditing cash flows over some probationary period of time and seizing them if malfeasance is detected. For example, in Buera, Kaboski, and Shin (2011), an entrepreneur who defaults gains full access to the credit market in the subsequent period; the contract is designed, though, so default will not happen. Long-run punishment strategies are important for achieving efficient contracts. So, one could always ask if long-term contracts would better facilitate both capital accumulation and technology adoption.

Long-term contracts obtain more efficient allocations by using backloading strategies, where the rewards to the owners of firms are delayed until the desired outcomes are obtained. In fact, when productivity shocks are independently and identically distributed over time, contracts can be designed such that the deviations from first-best allocations are relatively small, as noted in Marcet and Marimon (1992). (Perhaps this result can be thought of as Midrigan and $\mathrm{Xu}$ (2014) on steroids.) But the structure of the technology being

\footnotetext{
${ }^{3}$ Strictly speaking, the random component of the productivity shocks in Midrigan and $\mathrm{Xu}$ (2014) follows a Markov chain, but the shocks are tuned to resemble an AR(1) process.

${ }^{4}$ The upgrading appears to occur quickly. This can be gleaned from Midrigan and Xu (2014, Table 1). In the extension, younger firms grow three times faster (relative to older firms) than in the benchmark model, and additionally, as compared with the South Korean data.

${ }^{5}$ Again, in their extension, small firms grow far too quickly compared with the South Korean data, as noted in footnote 4 .
} 
financed matters for this result. It is shown here that this is no longer the case when the return structure offered from a technology is generalized. It may be impossible to write contracts that allow for certain technologies to be funded. If an investment cannot be funded with a long-term contract, then it cannot be funded with a sequence of short-term contracts, because a long-term contract can always be written to mimic a succession of short-term ones. In the analysis here, India and Mexico do not adopt the advanced technology even though long-term financial contracts can be written.

\section{EMPIRICAL EVIDENCE ON THE AVAILABILITY OF FINANCIAL INFORMATION AND THE COST OF ENFORCING CONTRACTS}

Is the ability of a nation's financial system to produce information about a firm's finances and to enforce contracts important for its level of output and TFP? Some direct evidence on this question is presented now. ${ }^{6}$ Bushman, Piotroski, and Smith (2004) constructed an index measuring financial transparency in firms across countries. The index is based on six series for each country. The first series measures disclosures about research and development (R\&D), capital investments, accounting methods, and whether disclosures are broken down across geographic locations, product lines, and subsidiaries. The second measure reflects information about corporate governance, such as the identity and remuneration of key personnel and the ownership structure of the firm. The quality of the information provided by the accounting principles adopted is captured in the third measure. The frequency and timeliness of financial reporting are given in the fourth series. The amount of private information acquisition by private analysts is captured by the number of analysts in a country following large firms. This constitutes the fifth series. The last series proxies for the quality of financial reporting by the media. Bushman, Piotroski, and Smith (2004) aggregated these six series using factor analysis into a single index of financial transparency, dubbed "info" here. (Info can be thought of as reflecting the monitoring variable, $z$, in the subsequent analysis.) Figure 1 presents scatterplots showing how GDP and TFP are related to this index representing the production of financial information. Both GDP and TFP are positively associated with the index measuring the production of financial information. The relationship is quite tight.

Next, an index is constructed that measures the cost of enforcing contracts in various countries. The underlying data are obtained from the World Bank's Doing Business database. In particular, three series are used. The first measures the cost of settling a business dispute. The second series records the number of procedures that must be filed to resolve a dispute. The number of days required to settle a dispute constitutes the last index. These three series

\footnotetext{
${ }^{6}$ The data used in this section are discussed in the Data Appendix (Appendix B) of the Supplemental Material (Cole, Greenwood, and Sanchez (2016b)).
} 

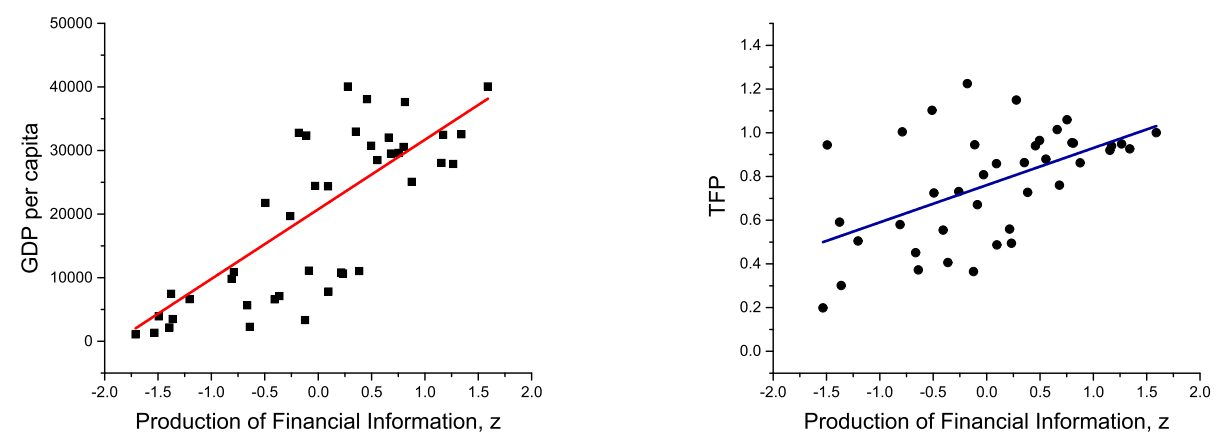

FIGURE 1.-The relationship between the production of financial information, on the one hand, and GDP per capita (left panel) and TFP (right panel) on the other hand.

are aggregated up using factor analysis into a single index reflecting the cost of contract enforcement, called "enfor." (Enfor can be taken as a proxy for the costly cash-flow control parameter, $\psi$, in subsequent formal analysis.) Figure 2 presents scatterplots showing the relationship of GDP and TFP to this index. Both GDP and TFP are negatively related to the cost of contract enforcement. The relationship between the cost of contract enforcement, on the one hand, and GDP or TFP, on the other, is cloudier than the relationship between the production of financial information and either of the latter two variables. Still, the relationships plotted in Figure 2 are statistically significant (at the 1 percent level).

Table I presents the results of some regression analysis. This analysis is intended for illustrative purposes only. ${ }^{7}$ In particular, both GDP and TFP are
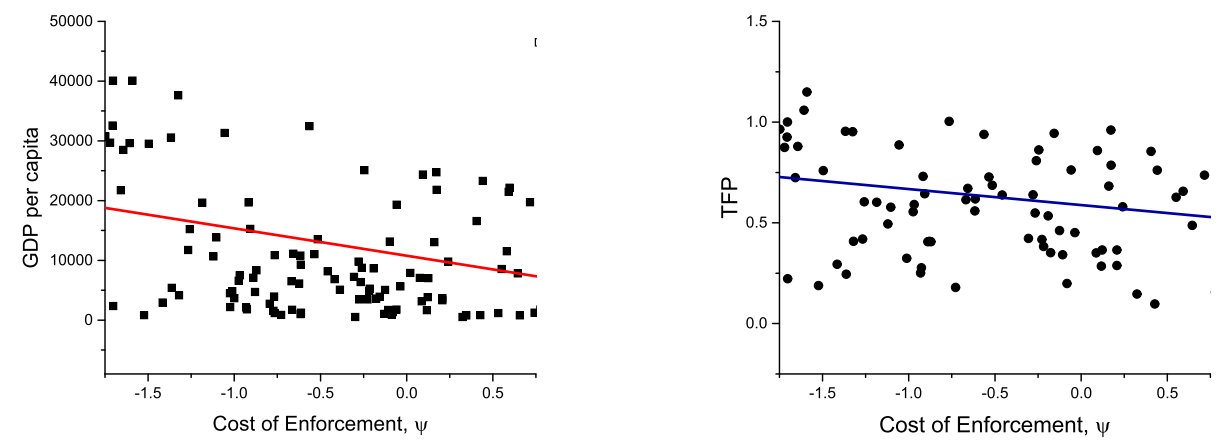

FIGURE 2.-The relationship between the cost of enforcing contracts, on the one hand, and GDP per capital (left panel) and TFP (right panel) on the other hand.

${ }^{7}$ A more careful analysis would proceed along the line of the papers surveyed in Levine (2005) and would constitute a paper in its own right. 
TABLE I

CROSS-COUNTRY REGRESSION RESULTS ${ }^{\mathrm{a}}$

\begin{tabular}{lcccc}
\hline \hline Variable & \multicolumn{2}{c}{$\ln ($ GDP per capita $)$} & \multicolumn{2}{c}{$\ln (\mathrm{TFP})$} \\
\hline Information, $z$ & $0.688^{* * *}$ & $0.605^{* * *}$ & $0.199^{* *}$ & $0.203^{* *}$ \\
Cost of enforcement, $\psi$ & $(0.133)$ & $(0.129)$ & $(0.085)$ & $(0.092)$ \\
& $-0.370^{* * *}$ & $-0.326^{* * *}$ & $-0.155^{* * *}$ & $-0.157^{* * *}$ \\
Credit-to-GDP ratio & $(0.082)$ & $(0.083)$ & $(0.036)$ & $(0.038)$ \\
& & 0.279 & & -0.013 \\
Constant & $9.272^{* * *}$ & $(0.250)$ & & $0.112)$ \\
& $(0.102)$ & $(0.208)$ & $-0.479^{* * *}$ & $-0.462^{* * *}$ \\
$R$-squared & 0.752 & 0.760 & $0.058)$ & $(0.106)$ \\
Number of observations & 42 & 42 & 0.513 & 0.513 \\
& & & 40 & 40 \\
\hline
\end{tabular}

a All data sources are discussed in the Data Appendix of the Supplemental Material. Robust standard errors listed in parentheses; ${ }^{*} p<0.1{ }^{* *} p<0.05{ }^{* * *} p<0.01$.

positively related with info and negatively associated with enfor. They are also economically and statistically significant. If Kenya increased its production of financial information to the U.S. level, then its GDP (per capita) and TFP would rise by 215 and 62 percent, respectively. Similarly, by reducing the cost of enforcing contracts to the U.S. level, Bangladesh could increase its GDP and TFP by 159 and 69 percent, respectively. Interestingly, when a traditional measure of the efficiency of financial intermediation is added to these regressions, the private-credit-to-GDP ratio (labeled "findev"), it is statistically insignificant. The coefficient on this variable in the regression for TFP even takes the wrong sign. When taking these coefficients at face value (even though they are not significantly different from zero), an increase in Bolivia's credit-to-GDP ratio to the U.S. level would boost its GDP by 37 percent and reduce its TFP by 1.7 percent. Two measures of collateral requirements and a measure of access to financial markets were also used as the third variable. They, too, are insignificant. All in all, these regressions suggest that the ability of a nation's financial system to produce information and enforce contracts is important for output and TFP.

\section{THE ENVIRONMENT}

At the heart of the analysis is the interplay between firms and financial intermediaries. This interaction is studied in steady-state general equilibrium. Firms produce output in the economy. They do so using capital and labor. New firms are started by entrepreneurs. The entrepreneur selects a blueprint for his firm from a portfolio of plans. He can operate only one project. Implementing this blueprint requires working capital. While an entrepreneur may have some personal funds, in general this working capital is obtained from financial intermediaries. Projects differ by the payoff structures they promise. For example, 
some projects offer low returns, but ones that materialize quickly without much investment. Others promise high returns. These projects are risky in the sense that the potential high returns will unfold out in the more distant future while the ventures may require extended periods of finance.

Intermediation is competitive. Thus, in equilibrium, intermediaries will earn zero profits. Intermediaries borrow funds from consumers/workers in the economy at a fixed rate of return. The structure of a financial contract offered by an intermediary will depend on the type of venture being funded, the fraction of the start-up costs of the project the entrepreneur can self-finance, input prices, and the state of the financial system. Of course, an entrepreneur will choose the most profitable blueprint to implement. For certain blueprints, it is not always possible for an intermediary to offer an entrepreneur a financial contract that will generate positive profits. Finally, in addition to supplying intermediaries with savings, consumers/workers provide labor to firms. Since consumers/workers play an ancillary role in the analysis, they are relegated to the background. ${ }^{8}$

\section{VENTURES}

The theory of entrepreneurship here is simple. Each period, there is a fixed amount of risk-neutral entrepreneurs that can potentially start new firms. Let $\mathcal{T}$ denote the set of available technologies in the world and $\tau \in \mathcal{T}$ represent a particular technology within this set. Entrepreneurs differ by the types of technology that they can operate, indexed by $\mathfrak{t} \in \mathcal{T}$, and in the amount of funds they have, $f \in \mathcal{F} \equiv[0, \bar{f}]$. Let the (non-normalized) distribution for potential type-t entrepreneurs over funds be represented by $\Phi_{t}(f): \mathcal{F} \rightarrow[0, \infty)$. A type- $t$ entrepreneur can start up and run a project of type $\tau \leq \mathfrak{t}$. Think about higher levels of $\tau$ as corresponding to more advanced technologies. Thus, an entrepreneur that can run technology $\nu \in \mathcal{T}$ can also operate any simpler one $\tau<\nu$. The entrepreneur faces a disutility cost, $\varepsilon_{\tau}$, measured in terms of consumption, connected with operating technology $\tau$. Envision $\varepsilon_{\tau}$ as representing the disutility of acquiring the skills necessary for operating a technology or as the disutility associated with running it. ${ }^{9}$ An entrepreneur can operate only one firm at a time.

\footnotetext{
${ }^{8}$ It also does not matter whether the analysis is considered as modeling (i) a closed economy in a steady state where the real interest rate earned by consumer/workers is equal to the rate of time preference or (ii) a small, open economy where consumer/workers can borrow or lend at some fixed real interest rate.

${ }^{9}$ The determination of who becomes an entrepreneur is of secondary importance for the analysis undertaken here. Interested readers are referred to the work of Buera, Kaboski, and Shin (2011) and Guner, Ventura, and Xu (2008) to see how such a consideration could be appended onto the current analysis. Abstracting from this factor allows the current work to focus on the novel aspects of the analysis.
} 


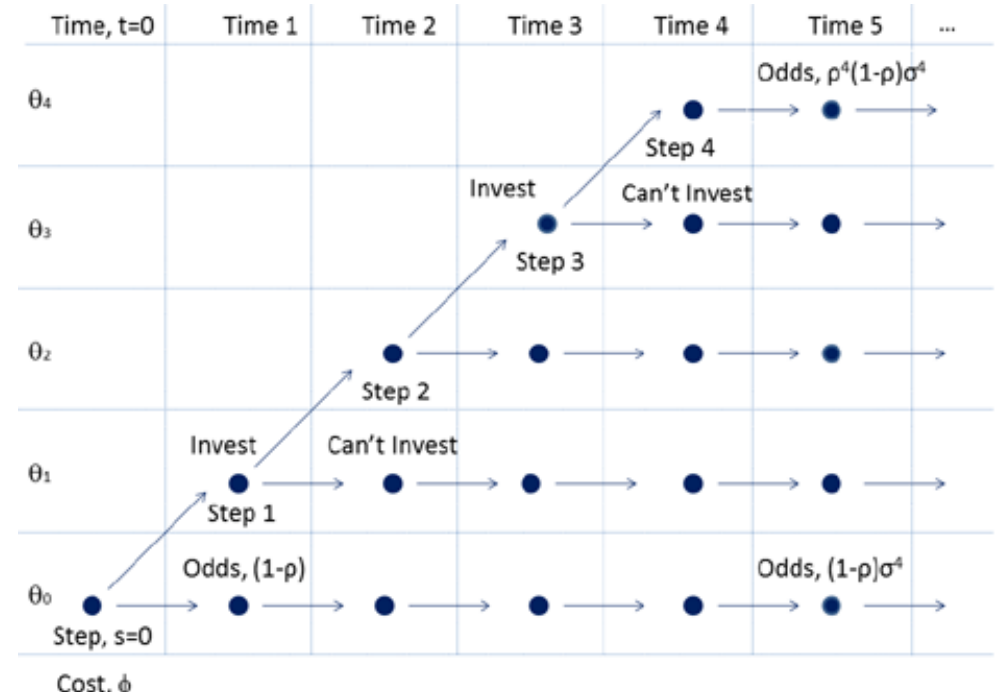

FIGURE 3.-Possible productivity paths for a venture over its lifetime.

A new firm started by an entrepreneur can potentially produce for $T$ periods, indexed by $t=1,2, \ldots, T$. There is a start-up period denoted by $t=0$. Here the firm must incur a fixed cost connected with entry that is represented by $\phi$. Associated with each new firm is a productivity ladder $\left\{\theta_{0}, \theta_{1}, \ldots, \theta_{S}\right\}$, where $S \leq T$. As mentioned earlier, the firm's blueprint or type is denoted by $\tau$. This indexes the vector $\left\{\theta_{0}, \theta_{1}, \ldots, \theta_{S}, \phi\right\}$. An entrepreneur selects the type of the blueprint for his firm, $\tau$, from a portfolio of available plans, $\mathcal{T}$. Again, only one plan can be implemented.

Figure 3 illustrates potential productivity paths for a firm over its lifetime. The firm enters a period at some step on the productivity ladder from the previous period. This step has an associated level of productivity. Now, suppose that at time $t-1$, the firm is at step $s-1=t-1$; that is, the firm is at a point along the diagonal in Figure 3. (The diagonal of the ladder plays an important role in the analysis.) At time $t-1$, the firm can invest in new capital for period $t$. With probability $\rho$, the firm moves up the ladder to the next step, $s$, which has productivity $\theta_{s}$. With probability $1-\rho$, the project stalls at the previous step $s-1$ and keeps the productivity level $\theta_{s-1}$, implying that the move up the ladder was unsuccessful. If a stall occurs, then productivity remains at its previous level, $\theta_{s-1}$, forever after. Capital then becomes locked in place and cannot be changed. Note that the investment in capital is made before it is known whether $\theta_{s-1}$ will move up in period $t=s$ to $\theta_{s}$. At the end of each period, the firm faces a survival probability of $\sigma$. Assume that an entrepreneur dies with his firm. The productivity ladder is somewhat reminiscent of Aghion and Howitt (1992). 
In the $t$ th period of its life, the firm will produce output, $o_{t}$, according to the diminishing-returns-to-scale production function

$$
o_{t}=\theta_{s}\left[\tilde{k}_{t}^{\omega}\left(\chi l_{t}\right)^{1-\omega}\right]^{\alpha} \quad \text { with } \quad 0<\alpha, \omega<1,
$$

where $\widetilde{k}_{t}$ and $l_{t}$ are, respectively, the inputs of physical capital and labor that it employs. Here $\chi$ is a fixed factor reflecting the productivity of labor in a country; this factor will prove useful for calibrating the model. Denote the rental rate for physical capital by $r$ and the wage for labor by $w$. The firm finances the input bundle, $\left(\widetilde{k}_{t}, l_{t}\right)$, that it will hire in period $t$ using working capital provided by the intermediary in period $t-1$.

Focus on the amalgamated input, $k_{t} \equiv \widetilde{k}_{t}^{\omega}\left(\chi l_{t}\right)^{1-\omega}$. The minimum cost of purchasing $k$ units of the amalgamated input will be

$$
\left[\chi^{\omega-1}\left(\frac{r}{\omega}\right)^{\omega}\left(\frac{w}{1-\omega}\right)^{1-\omega}\right] k=\min _{\widetilde{k}_{t}, l_{t}}\left\{r \tilde{k}+w l: \tilde{k}^{\omega}(\chi l)^{1-\omega}=k\right\} .
$$

Thus, the cost of purchasing one unit of the amalgam, $q$, is given by

$$
q=\chi^{\omega-1}\left(\frac{r}{\omega}\right)^{\omega}\left(\frac{w}{1-\omega}\right)^{1-\omega}
$$

The cost of the intermediary providing $k$ units of the amalgamated input is then $q k$. This represents the working capital, $q k$, provided by the intermediary to the firm. In what follows, $k$ is referred to as the working capital for the firm, even though strictly speaking it should be multiplied by $q$. The rental rate, $r$, consists of the interest and depreciation linked with the physical capital. It is exogenous in the analysis: In a steady state, the interest rate will be pinned down by the consumer/worker's rate of time preference, modulo country-specific distortions such as import duties on physical capital. The wage rate, $w$, will also have an interest component built into it. The wage rate will be determined endogenously. Hence, the cost of purchasing one unit of the amalgam, $q$, will be dictated by the equilibrium wage rate, $w$, via (1).

Finally, it is also easy to deduce that the quantities of physical capital and labor required to make $k$ units of the amalgam are given by

$$
\tilde{k}=\left(\frac{w}{r} \frac{\omega}{1-\omega}\right)^{1-\omega} \chi^{\omega-1} k
$$

and

$$
l=\left(\frac{w}{r} \frac{\omega}{1-\omega}\right)^{-\omega} \chi^{\omega-1} k
$$




\section{INTERMEDIARIES}

Intermediation is a competitive industry. An intermediary borrows from consumers/workers and enters into financial contracts with new firms to supply working capital for the latter's ventures. The entrepreneur starting a new firm has some personal funds of his own, $f$. He can choose to use some or all of his funds to finance part of the venture. At the time of the contract, the intermediary knows the firm's productivity ladder, $\left\{\theta_{0}, \theta_{1}, \ldots, \theta_{S}\right\}$, and its fixed cost, $\phi$. The contract specifies, among other things, the funds that the intermediary will invest in the firm over the course of its lifetime and the payments that the firm will make to the intermediary. These investments and payments are contingent on reports that the firm makes to the intermediary about its position on the productivity ladder. The intermediary cannot observe without cost the firm's position on the productivity ladder. Specifically, in any period $t$ of the firm's life, the intermediary cannot see $o_{t}$ or $\theta_{s}$.

Now, suppose that in period $t$, the firm reports that its productivity level is $\theta_{r}$, which may differ from the true level $\theta_{s}$. The intermediary can choose whether it wants to monitor the firm's report. The success of an audit in detecting an untruthful report is a random event. The intermediary can choose the odds, $p$, of a successful audit. Write the cost function for monitoring as follows:

$$
C(p, k ; q, z)=q\left(\frac{k}{z}\right)^{2}\left(\frac{1}{1-p}-1\right) p .
$$

This cost function has four noteworthy properties. First, it is increasing and convex in the odds, $p$, of a successful audit. When $p=0$, both $C(0, k ; q, z)=$ 0 and $C_{1}(0, k ; q, z)=C_{2}(0, k ; q, z)=0 ;$ as $p \rightarrow 1$, both $C(p, k ; q, z) \rightarrow \infty$ and $C_{1}(p, k ; q, z) \rightarrow \infty$. Second, the marginal and total costs of monitoring are increasing in the price of the amalgam, $q$; that is, $C_{3}(p, k ; q, z)>0$ and $C_{13}(p, k ; q, z)>0$. This is a desirable property if the amalgamated input must be used for monitoring. Third, the cost is increasing and convex in the size of the project as measured by the amalgamated input $k$; that is, $C_{2}(p, k ; q, z)>$ 0 and $C_{22}(p, k ; q, z)>0$. A larger scale implies there are more transactions to monitor. Detecting fraud will be harder. Fourth, the cost of monitoring is decreasing in the productivity of the financial sector, which is represented by $z$. (To simplify notation, the dependence of $C$ on $q$ and $z$ is suppressed when not needed.)

\section{THE CONTRACT PROBLEM}

The date- 0 contract problem between an entrepreneur and an intermediary is now formulated. To start with, the probability distribution for the firm 
arriving on step $s$ (or having productivity level $\theta_{s}$ ) at date $t$ is given by

$$
\operatorname{Pr}(s, t)= \begin{cases}\rho^{s} \sigma^{s-1} & \text { if } s=t \\ \rho^{s}(1-\rho) \sigma^{t-1} & \text { if } s<t \\ 0 & \text { if } s>t .\end{cases}
$$

The discount factor for both firms and intermediaries is denoted by $\beta$.

A financial contract between an entrepreneur and intermediary will stipulate the following for each step/date pair, $(s, t)$ : (i) the quantities of working capital to be supplied by the intermediary to the firm, $k(s, t)$; (ii) a schedule of payments by the firm to the intermediary, $x(s, t)$; and (iii) audit detection probabilities, $p(s, t)$. The contract also specifies the amount of funding, $\widetilde{f}$, that the entrepreneur will invest in the project. Take the entrepreneur as turning over these funds to the intermediary at the start of the project. Because a large number of competitive intermediaries are seeking to lend to each firm, the optimal contract will maximize the expected payoff of the firm, subject to an expected nonnegative profit constraint for the intermediary. The problem is formulated as the truth-telling equilibrium of a direct mechanism because the revelation principle applies. When a firm is found to have misrepresented its productivity, the intermediary imposes the harshest possible punishment: It shuts the firm down. Since the firm has limited liability, it cannot be asked to pay out more than its output in any period. The contract problem between the entrepreneur and intermediary is

$$
v=\max _{\{k(s, t), x(s, t), p(s, t), \tilde{f\}}} \sum_{t=1}^{T} \sum_{s=0}^{\min \{t, S\}} \beta^{t}\left[\theta_{s} k(s, t)^{\alpha}-x(s, t)\right] \operatorname{Pr}(s, t)+f-\tilde{f},
$$

subject to

$$
\begin{aligned}
& \theta_{s} k(s, t)^{\alpha}-x(s, t) \geq 0 \quad \text { for } \quad s=\{0, \ldots, \min \{t, S\}\} \text { and all } t, \\
& \sum_{t=u}^{T} \sum_{s=u}^{\min \{t, S\}} \beta^{t}\left[\theta_{s} k(s, t)^{\alpha}-x(s, t)\right] \operatorname{Pr}(s, t) \\
& \quad \geq \sum_{t=u}^{T} \sum_{s=u}^{\min \{t, S\}} \beta^{t}\left[\theta_{s} k(u-1, t)^{\alpha}-x(u-1, t)\right] \\
& \quad \times \prod_{n=u}^{t}[1-p(u-1, n)] \operatorname{Pr}(s, t) \\
& \quad \text { for all } u \in\{1, \ldots, S\}, \\
& k(s, s)=k(s-1, s) \quad \text { for all } s \leq S
\end{aligned}
$$




$$
\begin{aligned}
& k(s-1, t)=k(s-1, s) \quad \text { for } \quad 1 \leq s<S \text { and } t \geq s+1, \\
& k(S, t)=k(S, S) \quad \text { for } \quad t>S,
\end{aligned}
$$

and

$$
\begin{aligned}
& \sum_{t=1}^{T} \sum_{s=0}^{\min \{t, S\}} \beta^{t}[x(s, t)-C(p(s, t), k(s, t))-q k(s, t)] \operatorname{Pr}(s, t)-\phi+\tilde{f} \\
& \quad \geq 0 \\
& f-\tilde{f} \geq 0 .
\end{aligned}
$$

The objective function in $(\mathrm{P} 2)$ represents the expected present value of the profits for the firm, in addition to the entrepreneur's initial wealth net of what he contributes to the project. This is simply the expected present value of the gross returns on working capital investments, minus the payments that the firm must make to the intermediary, plus the entrepreneur's leftover wealth. The maximized value of this is denoted by $v$, which represents the value of the enterprise to the entrepreneur. The value of the enterprise, $v$, will be a function of the amount of funds the entrepreneur possesses, $f$; the price of inputs, $q$; the state of the financial system, $\psi$ and $z$; and the type of technology that is being operated, $\tau$ (note that $\tau$ has been suppressed in the above contracting problem to ease notation). Equation (6) is the limited liability constraint for the firm. The intermediary cannot take more than the firm produces at the step/date combination $(s, t)$.

The incentive constraint for a firm is specified by (7). This constraint is imposed on the firm at the state/date combinations where there is a new productivity draw; that is along the diagonal in Figure 3. Since no information is revealed at dates and states where there is not a new productivity draw, the firm can be treated as not making a report and hence as not having an incentive constraint at such nodes. ${ }^{10}$ The left-hand side of the constraint shows the value to the firm when it truthfully reports that it is currently at the step/date pair $(u, u)$, for all $u \in\{1, \ldots, S\}$. The right-hand side gives the value from lying and reporting that the pair is $(u-1, u)$, or that a stall has occurred. Suppose that the firm lies at time $u$ and reports that its state is $u-1$. Then, in period $t \geq u$, the firm will keep the cash flow $\theta_{s} k(u-1, t)^{\alpha}-x(u-1, t)$, provided that it is not caught cheating. The odds of the intermediary not detecting this fraud are given by $\prod_{n=u}^{t}[1-p(u-1, n)]$, since the intermediary will engage in

\footnotetext{
${ }^{10}$ The validity of this is established in Cole, Greenwood, and Sanchez (2016a). There, a more general problem is formulated where reports are allowed at all dates and times. These reports are general in nature and can be inconsistent over time or infeasible; for example, the firm can make a report that implies that it lied in the past. It is shown that any contract that is feasible for this more general formulation is also feasible for the restricted problem presented above and vice versa.
} 
auditing from time $u$ to $t$. One would expect that in (7), the probabilities for arriving at an $(s, t)$ pair should be conditioned on starting from the step/date combination $(u, u)$. This is true; however, note that the initial odds of landing at $(u, u)$ are embodied in a multiplicative manner in the $\operatorname{Pr}(s, t)$ terms and these will cancel out of both sides of (7). Thus, the unconditional probabilities, or the $\operatorname{Pr}(s, t)$ 's, can be used in (7).

In each period $t-1=s-1$, when there is not a stall, the contract will specify a level of working capital for the next period, $t=s$. This is done before it is known whether there will be a stall in the next period. Therefore, the value of the working capital in the state where productivity grows, $k(s, s)$, will equal the value in the state where it does not, $k(s-1, s)$. This explains equation (8). The information constraint is portrayed in Figure 4 by the vertical boxes defined by the solid lines. The two working capitals within each vertical box must have the same value.

Equation (9) is an irreversibility constraint on working capital. Specifically, if a productivity stall occurs in period $s$, working capital becomes locked in at its current level, $k(s-1, s)$. The irreversibility constraint is illustrated by the horizontal boxes drawn with the dashed-dotted lines in Figure 4. All working capitals within a horizontal box take the same value. Envision a plant as having a putty-clay structure: In the event of a stall, all inputs become locked in.

The penultimate constraint (10) stipulates that the intermediary expects to earn positive profits from its loan contract. At node $(s, t)$, the intermediary will earn $x(s, t)-C(p(s, t), k(s, t))-q k(s, t)$ in profits after netting out both the cost of monitoring and raising the funds for the working capital investment. In

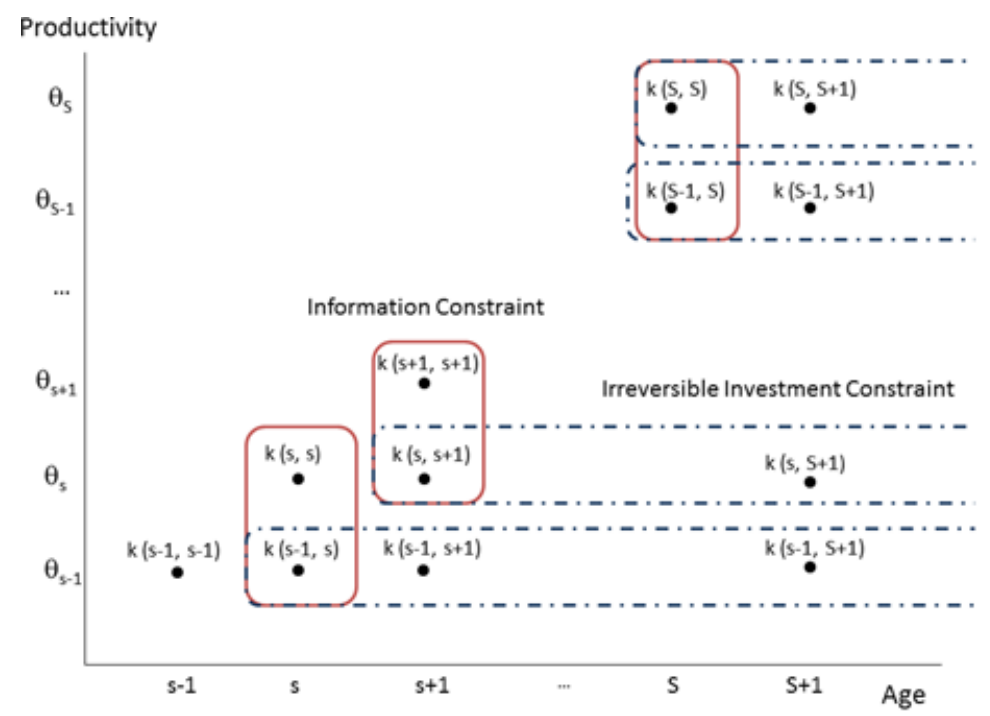

FIGURE 4.-The information and irreversibility constraints. 
period 0 , the intermediary collects the start-up funds, $\widetilde{f}$, from the entrepreneur and finances the up-front fixed cost, $\phi$, for the project. Finally, equation (11) is the self-financing constraint. It simply states that the entrepreneur cannot invest more in the venture than he has.

The contract between the entrepreneur and the intermediary specifies a plan for investment, monitoring, and payments such that the firm always truthfully reports productivity. This plan generally leads to a suboptimal level of investment due to the need to provide incentives so that the firm will always report the true state of productivity. Intuitively, one might think that this incentive problem will be reduced if the entrepreneur uses some of his own money to start up the firm. In fact, the entrepreneur should invest everything in his project. This yields an expected gross return on investment at least as great as the $1 / \beta$ that the entrepreneur can earn from depositing his funds in a savings account with an intermediary.

LEMMA 1-Go All In: It is weakly efficient to set $\tilde{f}=f$.

PROOF: See Theory Appendix A.2 (Supplemental Material).

Q.E.D.

Suppose that the firm reports at time $t=u$ that the technology has stalled at step $u-1$. If the incentive constraint is binding at step $u$, then the intermediary should monitor the firm over the remainder of its life. As the right-hand side of (7) shows, this monitoring activity reduces the firm's incentive to lie. In fact, a feature of the contract is that the firm will never lie, precisely because the incentive constraint (7) always holds.

LEMMA 2-Trust but Verify: Upon a report by the firm at time $u$ of a stall at node $(u-1, u)$, for $u=1,2, \ldots, S$, the intermediary will monitor the project for the remaining time, $t=u, u+1, \ldots, T$, contingent upon survival, if and only if the incentive constraint (7) binds at node $(u, u)$.

PROOF: See Theory Appendix A.4 (Supplemental Material).

Q.E.D.

How should the intermediary schedule the flow of payments owed by the firm, $x(s, t)$ ? To encourage the firm to always tell the truth, the intermediary should backload the rewards that the firm can earn. In particular, it is (weakly) optimal to let the firm realize all of its awards only upon arrival at the terminal node $(S, T)$. The intermediary should take away all the cash flow from the firm before this terminal node by setting $x(s, t)=\theta_{s} k(s, t)^{\alpha}$ for $(s, t) \neq(S, T)$. It should then give the firm at node $(S, T)$ all of the expected accrued profits from the project. This amounts to a negative payment from the firm to the intermediary at this time so that $x(S, T) \leq 0$. The profits from the enterprise will amount in expected present-value terms to $\sum_{t=1}^{T} \sum_{s=0}^{\min \{t, S\}} \beta^{t}\left[\theta_{s} k(s, t)^{\alpha}-\right.$ $C(p(s, t), k(s, t))-q k(s, t)] \operatorname{Pr}(s, t)-\phi+f \geq 0$. There may be other payment schedules that are equally efficient but none can dominate this one. 
LEMMA 3-Backloading: An optimal payment schedule from the firm to the intermediary, $\{x(s, t)\}$, is given by

1. $x(s, t)=\theta_{s} k(s, t)^{\alpha}$, for $0 \leq s \leq S, s \leq t, 1 \leq t \leq T$, and $(s, t) \neq(S, T)$;

2. $x(S, T)=\theta_{S} k(S, T)^{\alpha}-\left\{\sum_{t=1}^{T} \sum_{s=0}^{\min \{t, S\}} \beta^{t}\left[\theta_{s} k(s, t)^{\alpha}-C(p(s, t), k(s, t))-\right.\right.$ $q k(s, t)] \operatorname{Pr}(s, t)-\phi+f\} /\left[\beta^{T} \operatorname{Pr}(S, T)\right] \leq 0$.

PROOF: See Theory Appendix A.5 (Supplemental Material).

Q.E.D.

\section{THE CONTRACT WITH COSTLY CASH-FLOW CONTROL}

The theory developed up to this point stresses the role of monitoring in designing an efficient contract. The ability to monitor reduces the incentive of the firm to misrepresent its current situation and misappropriate funds, which makes it easier for the intermediary to recover its investment and to finance technology adoption. When monitoring is very costly, an intermediary must rely primarily on a backloading strategy to create the incentives for truthful behavior. As will be seen in the quantitative illustration, which is the subject of Section 9, it may not be possible to finance certain technologies absent the ability to monitor effectively. This is most likely to happen when a project has a large up-front investment and promises payoff streams tilted toward the end of the venture's lifetime. This is the case in the Mexico/United States example studied in Section 9. Here, Mexico has an inefficient monitoring technology relative to that of the United States. Thus, it is not able to adopt the advanced technology used by the United States, which has a large fixed cost and a very convex productivity profile that offers high returns skewed toward the end of the project's life. This occurs despite the fact that production costs are lower in Mexico. Instead, Mexico uses a less-productive technology, with a lower fixed cost and a productivity profile with returns that grow more slowly, which can be financed using a backloading strategy that requires little monitoring.

The costs of production in some countries are much lower than in Mexico. These lower production costs should imply bigger profits that, in turn, will make it easier for the intermediary to recover its investment. The intermediary could promise firms these extra profits at node $(S, T)$, which will increase the incentive effects of backloading. Maybe firms in such countries could implement the U.S. technology at their lower cost of production. If not, then what prevents them from using the Mexican technology? After all, it requires little in the way of monitoring services.

An extension to the baseline theory that provides one possible answer is now developed. The premise is that it is very costly for intermediaries in some countries to force firms to pay out all of their publicly acknowledged output. Perhaps a fraction of output inherently benefits the operators of firms in the 
form of perks, kickbacks, nepotism, and so on. The intermediary can offer enticements to the operators of firms so they will not do this, of course, but this is costly and limits the types of technology that can be implemented. The extended model is applied in Section 9 to India, where labor costs are extremely low.

\subsection{Adding Costly Cash-Flow Control}

Assume that a firm can openly take the fraction $\psi$ of output due to weak institutional structures. The intermediary cannot recover this output unless it catches, red-handed, the operators of the firm lying about the firm's state during an audit. The intermediary must design the contract in a manner such that the retention of output will be dissuaded. How does this affect the contract presented in (P2)?

Before characterizing the optimal contract for the extended setting, two observations are made:

1. The intermediary wants to design a contract that dissuades the firm from trying to retain the fraction $\psi$ of output at a node. To accomplish this, the payoff at any node from deciding not to retain part of output must be at least as great as the payoff from retaining a portion of output.

2. A retention request is an out-of-equilibrium move. Therefore, it is always weakly efficient for the intermediary to threaten to respond to a retention by lowering the firm's payoff to the minimum amount possible.

These two observations lead to a no-retention constraint at each node $(s, t)$ on the design of the contract:

$$
\begin{aligned}
& \sum_{j=t}^{T} \beta^{j}\left[\theta_{s} k(s, j)^{\alpha}-x(s, j)\right] \operatorname{Pr}(s, j) \\
& \quad \geq \psi \sum_{j=t}^{T} \beta^{j} \theta_{s} k(s, j)^{\alpha} \operatorname{Pr}(s, j) \\
& \quad \text { for } \quad 1 \leq s \leq S, s<t, 2 \leq t \leq T \text { (off-diagonal node) }
\end{aligned}
$$

and

$$
\begin{gathered}
\sum_{t=u}^{T} \sum_{s=u}^{\min \{t, S\}} \beta^{t}\left[\theta_{s} k(s, t)^{\alpha}-x(s, t)\right] \operatorname{Pr}(s, t) \\
\geq \psi \sum_{t=u}^{T} \sum_{s=u}^{\min \{t, S\}} \beta^{t} \theta_{s} k(u-1, t)^{\alpha} \operatorname{Pr}(s, t) \\
\quad \text { for } \quad 1 \leq u \leq S \text { (diagonal node). }
\end{gathered}
$$


The first constraint (12) applies to the case of a stall at state $s$. Here, productivity is stuck at $\theta_{s}$ forever. The second constraint (13) governs the situation where the firm can still move up the productivity ladder from node $(u, u)$. If the firm exercises its retention option, then the intermediary will keep the capital stock at $k(u-1, t)$; that is, it will no longer evolve with the state of the firm's productivity. Equation (9) then implies that the capital stock is locked in.

To formulate the contract problem with costly cash-flow control, simply append the no-retention constraints (12) and (13) to problem (P2). Lemma 2 still holds. Thus, the intermediary will again monitor the firm for the rest of its life whenever it claims that technological progress has stalled (if and only if the incentive constraint at the stalled step is binding). The payment schedule $\{x(s, t)\}$ now takes a different form. In the baseline version of the model, it is always optimal to make all payments to the firm at the terminal node $(S, T)$ to relax the incentive constraints. The retention option precludes this, however. To discourage the firm from exercising its retention option, it pays for the intermediary to make additional payments, $N(s, T)$, to the firm at the terminal date $T$ for all steps $s<S$ on the ladder, provided the firm does not exercise its retention option at any time before $T$. This payment should equal the expected present value of what the firm would receive if it exercised the retention option. Thus,

$$
N(s, T)=\psi \frac{\sum_{t=s+1}^{T} \beta^{t} \theta_{s} k(s, t)^{\alpha} \operatorname{Pr}(s, t)}{\beta^{T} \operatorname{Pr}(s, T)} \text { for } 0 \leq s<S .
$$

Hence, Lemma 3 now appears as Lemma 4. Observe how the necessity to provide retention payments reduces the size of the reward, $-x(S, T)$, that the intermediary can give to the firm if and when it reaches the end of the ladder or node $(S, T)$. Thus, retention payments reduce the intermediary's ability to redirect the firm's rewards (or cash flow) to the top of the ladder.

LEMMA 4-Backloading With Retention Payments: An optimal payment schedule from the firm to the intermediary, $\{x(s, t)\}$, is given by

1. $x(s, t)=\theta_{s} k(s, t)^{\alpha}$, for $0 \leq s \leq S, 1 \leq t<T$, and $s \leq t$;

2. $x(s, T)=\theta_{s} k(s, T)^{\alpha}-N(s, \bar{T})$, for $0 \leq s<S$;

3. $x(S, T)=\theta_{S} k(S, T)^{\alpha}-\left\{\sum_{t=1}^{T} \sum_{s=0}^{\min \{t, S\}} \beta^{t}\left[\theta_{s} k(s, t)^{\alpha}-C(p(s, t), k(s, t))-\right.\right.$ $\left.q k(s, t)] \operatorname{Pr}(s, t)-\sum_{s=0}^{S-1} \beta^{T} N(s, T) \operatorname{Pr}(s, T)-\phi+f\right\} /\left[\beta^{T} \operatorname{Pr}(S, T)\right]$, where $N(s, T)$ is specified by (14).

PROOF: See Theory Appendix A.5 (Supplemental Material). Q.E.D.

Backloading the retention payments helps to satisfy the incentive constraint. To understand why, suppose that the firm lies and declares a stall at node 
$(u, u)$. The intermediary will audit the firm from then on. Recall the intermediary can recover all output if it detects a lie at some node $(u, t)$, where $t \geq u$. Some firms will indeed stall and find themselves at node $(u-1, u)$. Under the old contract, a stalled firm would receive nothing because $x(u-1, t)=$ $\theta_{u-1} k(u-1, t)^{\alpha}$ for all $t>u-1$. Now the firm can exercise its retention option and take $\psi \theta_{u-1} k(u-1, t)^{\alpha}$ for $t>u-1$. A firm that is at node $(u, u)$, but declares that it is at $(u-1, u)$, would also like to claim this part of output. It can potentially do this provided it is not caught. To mitigate this problem, the intermediary gives the firm the accrued value of these retentions, $N(u-1, T)$, at the end of the contract, or time $T$, assuming that the latter survives. This reduces the incentive for a firm to lie and declare a stall at node $(u, u)$. A deceitful firm will receive the payment $N(u-1, T)$ only if it successfully evades detection along the entire path from $u$ to $T$. This happens with odds $\prod_{n=u}^{T}[1-p(u-1, n)]$.

Note how the intermediary's ability to monitor interacts with the firm's potential to retain output. The expected value of the retention payment from lying at $(u, u)$ is $N(u-1, T) \prod_{n=u}^{T}[1-p(u-1, n)]$, for all $u \in\{1, \ldots, S\}$. When monitoring is very effective, it is difficult for a masquerading firm to capture this payment, which reduces the incentive to lie. When monitoring is ineffective, it is easy to do this. The incentive to lie is then higher.

Finally, when is investment efficient? That is, when will investment match the level that would occur in a world where the intermediary can observe the firm's shock without cost? Suppose that after some state/date combination $\left(t^{*}, t^{*}\right)$ along the diagonal of the ladder that neither the incentive nor no-retention constraints, (7) and (13), ever bind again. Will investment be efficient from then on? Yes. ${ }^{11}$

LEMMA 5-Efficient Investment: Suppose that neither the incentive nor the diagonal-node no-retention constraints ever bind after node $\left(t^{*}, t^{*}\right)$ for $t^{*}<S$. Investment will be efficiently undertaken on arriving at the state/date combination $\left(t^{*}, t^{*}\right)$ (i.e., inputs will be at their efficient level from period $t^{*}+1$ on).

Proof: See Theory Appendix A.6 (Supplemental Material). Q.E.D.

\section{EQUILIBRIUM}

There is one unit of labor available in the economy. This must be split across all operating firms. Recall that a firm's type is given by $\tau \in \mathcal{T}$, which indexes the vector $\left\{\theta_{0}, \theta_{1}, \ldots, \theta_{S}, \phi\right\}$ connected with a particular productivity ladder and fixed cost. Again, the technologies are ordered so that higher $\tau$ 's correspond

\footnotetext{
${ }^{11}$ Some additional aspects of the contract problem are discussed in Cole, Greenwood, and Sanchez (2016a). Also, some simple two-period examples illustrating the contracting setup are presented.
} 
with more advanced technologies. An entrepreneur of type $\mathfrak{t} \in \mathcal{T}$ can potentially start a new firm of type $\tau \leq \mathfrak{t}$. He incurs the disutility cost, $\varepsilon_{\tau}$ (measured in terms of consumption), to operate a type- $\tau$ firm. Entrepreneurs may differ by the level of funds, $f$, that they bring to the project. The (non-normalized) distribution for potential type-t entrepreneurs over funds is represented by $\Phi_{\mathrm{t}}(f):[0, \bar{f}] \rightarrow[0, \infty)$.

Clearly, an entrepreneur will operate the technology that offers the largest surplus. The choice for a type-t entrepreneur with $f$ in funds is represented by $\tau^{*}(\mathfrak{t}, f)$, where

$$
\tau^{*}(\mathfrak{t}, f)=\arg \max _{\tau \leq \mathfrak{t}}\left[v(f ; \tau)-\varepsilon_{\tau}\right] .
$$

It may be the case that this entrepreneur does not want to operate any type of project, because $v\left(f, \tau^{*}\right)<\varepsilon_{\tau^{*}}$. Let the indicator function $I_{\tau}(\mathfrak{t}, f)$ denote whether a type-t entrepreneur with $f$ in funds will operate (or match with) a type- $\tau$ venture. It is defined by

$$
I_{\tau}(\mathfrak{t}, f)= \begin{cases}1 & \text { if } \tau=\arg \max _{\tau \leq \mathfrak{t}}\left[v(f ; \tau)-\varepsilon_{\tau}\right] \text { and } v(f ; \tau)-\varepsilon_{\tau} \geq 0 \\ 0 & \text { otherwise. }\end{cases}
$$

The entrepreneur's type, $t$, does not influence the terms of the financial contract specifying the firm's working capital and hence input usage. Represent the working capital and labor used at node $(s, t)$ in a type- $\tau$ firm, operated by an entrepreneur with $f$ in funds, by $k(s, t ; \tau, f)$ and $l(s, t ; \tau, f)$, respectively.

The labor market clearing condition for the economy then reads

$$
\begin{aligned}
& \sum_{\tau \in \mathcal{T}} \sum_{\mathfrak{t} \in \mathcal{T}} \int I_{\tau}(\mathfrak{t}, f) \sum_{t=1}^{T} \sum_{s=1}^{\min \{t, S\}}\left[l(s, t ; \tau, f)+l_{m}(s, t ; \tau, f)\right] \\
& \quad \times \operatorname{Pr}(s, t) d \Phi_{\mathfrak{t}}(f)=1
\end{aligned}
$$

where $l_{m}(s, t ; \tau, f)$ is the amount of labor that an intermediary will use at node $(s, t)$ monitoring a type- $\tau$ venture operated by an entrepreneur with funds $f$. Every period, some firms die; this death process is subsumed in the probabilities $\operatorname{Pr}(s, t)$. The quantity of the amalgamated input used in monitoring, $k_{m}(s, t ; \tau, f)$, is given by

$$
\begin{aligned}
& k_{m}(s, t ; \tau, f) \\
& \quad=\left[\frac{k(s, t ; \tau, f)}{z}\right]^{2}\left[\frac{1}{1-p(s, t ; \tau, f)}-1\right] p(s, t ; \tau, f) \quad(\text { cf. (4)), }
\end{aligned}
$$


which implies a usage of labor in the following amount:

$$
l_{m}(s, t ; \tau, f)=\left(\frac{w}{r} \frac{\omega}{1-\omega}\right)^{-\omega} \chi^{\omega-1} k_{m}(s, t ; \tau, f) \quad(\text { cf. (3)) } .
$$

A definition of the competitive equilibrium under study is now presented to crystallize the discussion so far. ${ }^{12}$

DEFINITION 1: For a given steady-state cost of capital, $r$, a stationary competitive equilibrium is described by (a) a set of working capital allocations, $k(s, t ; \tau, f)$, labor allocations, $l(s, t ; \tau, f)$ and $l_{m}(s, t ; \tau, f)$, and monitoring strategy, $p(s, t ; \tau, f)$; (b) a set of optimal matches between entrepreneurs and technologies represented by $I_{\tau}(t, f)$; and (c) an amalgamated input price, $q$, and wage rate, $w$, all such that

1. The working capital financing program, $k(s, t ; \tau, f)$, and the monitoring strategy, $p(s, t ; \tau, f)$, specified in the financial contract maximize the value of a type- $\tau$ venture for an entrepreneur with $f$ in funds, as set out by (P2), given the amalgamated input price, $q$. (Here (P2) should be amended to include the no-retention constraints (12) and (13).)

2. The set of optimal matches between entrepreneurs and technologies, as represented by $I_{\tau}(\mathfrak{t}, f)$, is specified by (16).

3. A type- $\tau$ venture operated by an entrepreneur with $f$ in funds hires labor, $l(s, t ; \tau, f)$, to minimize its costs in accordance with (P1), given wages, $w$, and the size of the loan, $k(s, t ; \tau, f)$, offered by the intermediary. (This implies that $\left.l(s, t ; \tau, f)=\{(w / r)[\omega /(1-\omega)]\}^{-\omega} k(s, t ; \tau, f).\right)$

4. The amount of labor, $l_{m}(s, t ; \tau, f)$, used to monitor a venture is given by (19) in conjunction with (18).

5 . The price of the amalgamated input, $q$, is dictated by $w$ in accordance with (1).

6. The wage rate, $w$, is determined so that the labor market clears, as written in (17).

\section{A QUANTITATIVE ILLUSTRATION}

Why might one country choose a different set of production technologies than another country? A quantitative illustration is presented to show that the financial mechanism proposed here offers some promise for explaining

\footnotetext{
${ }^{12}$ In Cole, Greenwood, and Sanchez (2016a), it was shown that an entrepreneur starting a new venture should commit all of his available funds to the project. When the firm self-finances some of the start-up costs, there is less incentive to cheat on the contract in an attempt to avoid paying some of the fixed costs. If the entrepreneur's funds are large enough, the project will be financed in the first-best manner. Additionally, it is established that if there is a distribution of funds across entrepreneurs in a country, then there may be a corresponding distribution over the technologies adopted by the entrepreneurs' firms.
} 
cross-country differences in technology adoption and, hence, income. There are many reasons, of course, why countries adopt different technologies: differences in the supplies of labor or natural resources that create a comparative advantage for certain types of firms; government regulations, subsidies, or taxes that favor certain forms of enterprise over others; and the presence of labor unions and other factors that may dissuade certain types of business. While these are valid reasons, the focus here is on differences in the efficiency of the financial system. This is done without apology, because abstraction is a necessary ingredient for theory. A formal empirical assessment of the mechanism, and a comparison with other explanations (including financial ones), is beyond the scope of this work. In what follows, assume that $z^{\mathrm{US}}>z^{\mathrm{MX}}=z^{\mathrm{IN}}$ and $\psi^{\mathrm{US}}=\psi^{\mathrm{MX}}<\psi^{\mathrm{IN}}$. So, monitoring is more efficient in the United States than in either Mexico or India, and the retention problem is more severe in India than in either the United States or Mexico.

In the quantitative illustration, there is a single type of entrepreneur who is free to adopt one of three technologies: advanced, intermediate, and entry level. Additionally, it is assumed that entrepreneurs have no start-up funds of their own $(f=0) .{ }^{13}$ The advanced technology has a (convex) productivity ladder that grows faster than the intermediate one (which also has a convex ladder), which in turn grows faster than the entry-level technology (which has a concave ladder). The fixed cost for the advanced technology is bigger than that of the intermediate one, which is larger than that of the entry-level technology. The advanced technology, with its convex payoff structure and high fixed cost, is difficult to implement without monitoring at high factor prices. It is also difficult to adopt at low factor prices when there is a costly cash-flow control problem. The entry-level technology with its very low fixed cost is easy to implement in the absence of monitoring and when there is a costly cash-flow control problem. A country's choice of technology depends on its factor prices and the state of its financial system. An equilibrium is constructed in which the United States will adopt the advanced technology, Mexico selects the intermediate one, and India chooses the entry-level technology.

\footnotetext{
${ }^{13}$ Denote the set of technologies by $\mathcal{T}=\{$ US, MX, IN $\}$, where US, MX, and IN represent the advanced, intermediate, and entry-level technologies, respectively. Let an entrepreneur's type be given by $\mathfrak{t}=\mathrm{US}$, implying that he can run any of the three technologies. Suppose that there is a large supply of entrepreneurs; that is, set $\Phi_{U S}(0)=\mathfrak{f}_{U S}$, where $f_{U S}$ is some large number. This implies that there is free entry into running a firm, as in Hopenhayn and Rogerson (1993). Assuming that only one technology, $\tau \in \mathcal{T}$, will be run in a country, the labor-market clearing condition (17) now appears as
}

$$
\sum_{t=1}^{T} \sum_{s=1}^{\min \{t, S\}}\left[l(s, t ; \tau, 0)+l_{m}(s, t ; \tau, 0)\right] \operatorname{Pr}(s, t) \mathfrak{e}_{\tau} \mathfrak{f}_{\mathrm{US}}=1,
$$

where $\mathfrak{e}_{\tau} \leq \mathfrak{f}_{\text {US }}$ is the equilibrium fraction of potential entrepreneurs that run a firm. 
Since the focus here is on the long run, let the length of a period be 5 years (a lustrum) and set the number of periods to 10 , so that $T=10$. Given this period length, the discount factor is set so $\beta=0.98^{5}$, slightly below the 3 percent return documented by Siegal (1992). This is a conservative choice since it gives backloaded long-term contracts a better chance. The weight on capital in the production function, $\omega$, is chosen so that $\omega=0.33$. A value of 0.85 is assigned to the scale parameter, $\alpha$. According to Guner, Ventura, and Xu (2008), this lies in the range of recent studies.

\subsection{Estimating the Input Prices}

A key input into the analysis is the price for the amalgamated input, $q$. Start with Mexico and the United States. ${ }^{14}$ The price of this input in Mexico relative to the United States is what is important. Normalize this price to be 1 for the United States, so that $q^{\mathrm{US}}=1$. (A superscript attached to a variable, either MX or US, denotes the relevant country of interest; viz., Mexico or the United States.) This can be done by picking an appropriate value for U.S. labor productivity, $\chi^{\mathrm{US}}$, given values for the rental rate on capital, $r^{\mathrm{US}}$, and the wage rate, $w^{\text {US }}$. How to do this is discussed below. Is the price for this input more or less expensive in Mexico? On the one hand, wages are much lower in Mexico. On the other hand, capital is more expensive and labor is less productive. Hence, the answer is unclear ex ante. Estimating the price of the input in Mexico, $q^{\mathrm{MX}}$, requires using equation (1) in conjunction with an estimate of the rental price of capital in Mexico, $r^{\mathrm{MX}}$, the wage rate, $w^{\mathrm{MX}}$, and the productivity of labor, $\chi^{\mathrm{MX}}$.

How is $q^{\mathrm{US}}$ set to 1 ? First, the rental rate on capital, $r^{\mathrm{US}}$, is pinned down. To do this, suppose that the relative price of capital in terms of consumption in the United States is 1 . Thus, $p_{k}^{\mathrm{US}} / p_{c}^{\mathrm{US}}=1$, where $p_{k}^{\mathrm{US}}$ and $p_{c}^{\mathrm{US}}$ are the U.S. prices for capital and consumption goods. Assume that annual interest plus depreciation in each country sum to 10 percent of the cost of capital. Hence, set $r^{\mathrm{US}}=\left(1.10^{5}-1\right) \times\left(p_{k}^{\mathrm{US}} / p_{c}^{\mathrm{US}}\right)=1.10^{5}-1$, which measures the cost of capital in terms of consumption. Second, a value for the wage rate, $w^{\mathrm{US}}$, is selected. This is obtained by dividing the annual payroll by the number of employees in all establishments in the manufacturing sector using the 2008 Annual Survey of Manufactures. Thus, $w^{\mathrm{US}}=\$ 47,501$. Last, given the above data for $r^{\mathrm{US}}$ and $w^{\mathrm{US}}$, the value for $\chi_{\mathrm{US}}^{\mathrm{US}}$ that sets $q^{\mathrm{US}}$ equal to 1 can be backed out using equation (1). This implies $\chi^{\mathrm{US}}=96,427$.

Turn now to Mexico. What is the value of $q^{\mathrm{MX}}$ ? Determining this value requires knowing $r^{\mathrm{MX}}, w^{\mathrm{MX}}$, and $\chi^{\mathrm{MX}}$. First, a value for the rental price of capital, $r^{\mathrm{MX}}$, is determined. The relative price of capital is estimated (from the Penn World Table) to be about 21 percent higher in Mexico than in the United States. Therefore, $\left(p_{k}^{\mathrm{MX}} / p_{c}^{\mathrm{MX}}\right) /\left(p_{k}^{\mathrm{US}} / p_{c}^{\mathrm{US}}\right)=1.21$, where

\footnotetext{
${ }^{14}$ All data sources used are discussed in the Data Appendix (Supplemental Material).
} 
$p_{k}^{\mathrm{MX}}$ and $p_{c}^{\mathrm{MX}}$ are the Mexican prices for capital and consumption goods. Therefore, $r^{\mathrm{MX}}=\left(1.10^{5}-1\right) \times\left(p_{k}^{\mathrm{MX}} / p_{c}^{\mathrm{MX}}\right)=\left(1.10^{5}-1\right) \times\left(p_{k}^{\mathrm{US}} / p_{c}^{\mathrm{US}}\right) \times$ $\left[\left(p_{k}^{\mathrm{MX}} / p_{c}^{\mathrm{MX}}\right) /\left(p_{k}^{\mathrm{US}} / p_{c}^{\mathrm{US}}\right)\right]=r^{\mathrm{US}} \times\left[\left(p_{k}^{\mathrm{MX}} / p_{c}^{\mathrm{MX}}\right) /\left(p_{k}^{\mathrm{US}} / p_{c}^{\mathrm{US}}\right)\right]=\left(1.10^{5}-1\right) \times 1.21$. This gives the rental price of capital in terms of consumption for Mexico.

Second, a real wage rate is needed for Mexico, or a value for $w^{\mathrm{MX}}$ is sought. Again, this is pinned down using data on the annual payroll and the total number of workers in manufacturing establishments; in this case, the data come from Mexico's National Institute of Statistics and Geography (INEGI). The result is $w^{\mathrm{MX}}=\$ 21,419$ once Mexican pesos are converted to U.S. dollars on a purchasing power parity basis.

Third, what is the productivity of labor in Mexico? A unit of labor in Mexico is taken to be 55 percent as productive as in the United States, following Schoellman (2012). So set $\chi^{\mathrm{MX}}=0.55 \times \chi^{\mathrm{US}}=53,035$. Finally, by using the obtained values for $r^{\mathrm{MX}}, w^{\mathrm{MX}}$, and $\chi^{\mathrm{MX}}$ in equation (1), it then follows that $q^{\mathrm{MX}}=0.9371$. The upshot is that the amalgamated input is 6 percent less expensive in Mexico relative to the United States.

Move now to India. The rental price of capital in India, $r^{\mathrm{IN}}$, is about 23 percent higher in India than in the United States (from the Penn World Table). Therefore, $r^{\mathrm{IN}}=\left(1.10^{5}-1\right) \times 1.23$. The real wage rate for India, $w^{\mathrm{IN}}$, will be chosen to approximate output per worker in the manufacturing sector relative to the United States. As a result, $w^{\mathrm{IN}}=\$ 7,000$, which is about 15 percent of the U.S. wage rate. Finally, what is the productivity of labor in India? A unit of labor in India is taken to be 35 percent as productive as in the United States. Here 1.6 years of education are added to the number in Barro and Lee (2013) to adjust their aggregate number upward to reflect the higher level of education in the manufacturing sector. The procedure developed in Schoellman (2012) is then used to obtain a measure of labor productivity. This leads to $\chi^{\mathrm{IN}}=33,750$. Finally, by plugging the obtained values for $r^{\mathrm{IN}}, w^{\mathrm{IN}}$, and $\chi^{\mathrm{IN}}$ into equation (1), it follows that $q^{\mathrm{IN}}=0.6$.

\subsection{Parameterizing the Technology Ladder}

There are nine unique rungs (out of eleven) on the technology ladder; the last three are the same. The generic productivity ladder is described by

$$
\theta_{s}=\ln \left[\bar{\theta}_{0}+\bar{\theta}_{1}(s+1)+\bar{\theta}_{2}(s+1)^{2}+\bar{\theta}_{3}(s+1)^{3}\right] \quad \text { for } \quad s=0, \ldots, 9 .
$$

The parameter values for this ladder are different for India, Mexico, and the United States. The odds of stalling are fixed over the age of a firm and are given by $\rho$. Let $\rho^{\mathrm{US}}>\rho^{\mathrm{MX}}=\rho^{\mathrm{IN}}$; that is, assume the odds of moving up the ladder for the advanced technology are greater than those for the other two ladders. 
The probability of surviving (until age $t$ ) is also allowed to differ across technologies. The survival probabilities follow the process

$$
\sigma_{t}=\sigma_{t-1}\left[1-\left(\bar{\sigma}_{0}+\bar{\sigma}_{1} t+\bar{\sigma}_{2} t^{2}\right)\right]^{5} \text { for } t=2, \ldots, 10, \text { with } \sigma_{1}=1 .
$$

This structure characterizing the odds of survival and stalling can easily be added onto the theory developed..$^{15}$ Finally, an upper bound on working capital is imposed. This is denoted by $\bar{k}$ and is common across the three technologies. ${ }^{16}$

\subsection{The Choice of Technology in India, Mexico, and the United States}

A quantitative illustration is now provided where India, Mexico, and the United States all choose to adopt different production technologies. The U.S. (or advanced) technology offers a productivity profile that grows much faster with age than the Mexican contour (which represents an intermediate-level technology). The start-up cost for the U.S. technology is higher than the Mexican one. Even though Mexican factor prices are slightly lower than in the United States, it is not profitable to operate the advanced technology in Mexico. This is because financing the advanced technology (at Mexican factor prices) requires a level of efficiency in monitoring that is too high for the Mexican financial system. Without efficient monitoring, it is not possible for financiers to recover the cost of investment. The intermediate-level technology does not require such a high level of monitoring efficiency. The productivity profile for the Indian technology is lower and flatter than the Mexican one. The cost of production in India $\left(q^{\mathrm{IN}}=0.6\right)$ is much less expensive than in Mexico $\left(q^{\mathrm{MX}}=0.94\right)$ and the United States $\left(q^{\mathrm{US}}=1\right)$. Therefore, at first glance, one would expect that India could profitably adopt the technology used in Mexico. But adopting the Mexican technology is not feasible for India because of a costly cash-flow control problem. This factor prevents financiers from recovering their up-front investment. Thus, India is forced to adopt the entry-level technology with a relatively flat productivity schedule but low fixed cost. The quantitative illustration is constructed so that the framework matches the size distribution of establishments by age that is observed for India, Mexico, and the United States. It also replicates the average size of firms in these three countries-in fact, for the United States, the entire size distribution is fit. These four sets of facts discipline the calibrated/estimated productivity ladders.

\footnotetext{
${ }^{15}$ See Cole, Greenwood, and Sanchez (2016a).

${ }^{16}$ This upper bound prevents the scale of a venture becoming unrealistically large as input prices drop to low levels. That is, the upper bound forces decreasing returns to bite more sharply at some point than the adopted Cobb-Douglas representation of the production function allows. This could be due to span of control or other problems.
} 


\subsubsection{Calibrating the Technology Ladders}

First, the survival probabilities are obtained from the Indian, Mexican, and U.S. data. In particular, a polynomial of the specified form is fit to the data from each country. It turns out that these survival probabilities are remarkably similar for Mexico and the United States. So, assume that they are the same.

Second, this leaves the parameters for describing productivity and the odds of a stall along the diagonal. These parameters are selected so that the model fits, as well as possible, several stylized facts about the Indian, Mexican, and U.S. economies. These facts are output per worker, average plant size, average growth in TFP over a plant's life, the (complementary) cumulative distribution of employment by establishment age, and the private-debt-toGDP ratio. The (complementary) distribution of employment by establishment age is characterized by a set of points. For the United States alone, the establishment size distribution in Lorenz-curve form is also added to the collection of stylized facts. So, let $D^{j}$ proxy for the $j$ th data target for the model and $M^{j}(p)$ represent the model's prediction for this data target as a function of the model's parameter vector $p$. The parameter vector $p$ is given by $p=\left\{\tau^{\mathrm{US}}, \tau^{\mathrm{IN}}, \tau^{\mathrm{MX}}, \bar{k}, \rho^{\mathrm{US}}, \rho^{\mathrm{MX}}, z^{\mathrm{US}}, \psi^{\mathrm{US}}, z^{\mathrm{MX}}, \psi^{\mathrm{IN}}\right\}$, where $\tau^{X} \equiv\left\{\bar{\theta}_{0}^{X}, \bar{\theta}_{1}^{X}, \bar{\theta}_{2}^{X}, \bar{\theta}_{3}^{X}, \phi^{X}\right\}$ denotes the technology ladder for country $X \in$ $\{\mathrm{US}, \mathrm{MX}, \mathrm{IN}\}$. Recall that $\rho^{\mathrm{IN}}=\rho^{\mathrm{MX}}, \psi^{\mathrm{MX}}=\psi^{\mathrm{US}}$, and $z^{\mathrm{ID}}=z^{\mathrm{MX}}$, so there is no need to include these three parameters in $p$. The vector $p$ is chosen using a minimum distance estimation procedure:

$$
\min _{p} \sum_{j}\left[D^{j}-M^{j}(p)\right]^{2} .
$$

The parameter values used in the simulation are reported in Table II.

Figure 5 shows the salient features of the technologies used in India, Mexico, and the United States. The productivity of a firm increases with a move up the ladder. The U.S. ladder has a convex/concave profile, while the Indian one is concave. The Mexican ladder lies between the other two. Note that the ascent is much steeper for a U.S. firm than a Mexican one. The productivity profile for the Indian ladder is lower and flatter than the Mexican one. The survival rate is higher for younger establishments in India than for plants in either Mexico or the United States (recall that the survival rates for the latter two countries are the same). The structure of the technology ladder, or the $\theta$ 's, is identified from the age distribution of employment in each country. ${ }^{17}$

Another parameter governing the technology ladder is the fixed cost, $\phi$. This number is selected as part of the minimization routine to hit the data targets; Buera, Kaboski, and Shin (2011) followed a similar strategy. The fixed costs

\footnotetext{
${ }^{17}$ A two-period example presented in Cole, Greenwood, and Sanchez (2016a) illustrates how this is done.
} 
TABLE II

The Parameter Values Used in the Simulations

\begin{tabular}{lccc}
\hline \hline & \multicolumn{3}{c}{ Value } \\
\cline { 2 - 4 } Parameter & United States & Mexico & India \\
\hline Discount factor, $\beta$ & $0.98^{5}$ & $0.98^{5}$ & $0.98^{5}$ \\
Production function, scale, $\alpha$, capital's share, $\omega$ & $0.8,0.33$ & $0.8,0.33$ & $0.8,0.33$ \\
Capital, upper bound, $\bar{k}$ & 12 & 12 & 12 \\
Fixed cost, $\phi$ & 0.255 & 0.015 & 0 \\
Labor efficiency, $\chi$ & 96,427 & 53,035 & 33,750 \\
Pr stall, $1-\rho$ & 0.31 & 0.6 & 0.6 \\
Steps along ladder, the $\sigma$ 's (productivity) & See Figure 5 & See Figure 5 & See Figure 5 \\
Pr survival at time $t$, the $\sigma$ 's & See Figure 5 & See Figure 5 & See Figure 5 \\
Input price, $q$ & 1.0 & 0.94 & 0.6 \\
Monitoring efficiency, $z$ & 1.75 & 0.50 & 0.50 \\
Retention, $\psi$ & 0.06 & 0.06 & 0.48 \\
\hline
\end{tabular}

associated with adopting the advanced technology are larger than those connected with the intermediate technology, which in turn are bigger than those linked with the entry-level one. As a fraction of GDP, these fixed costs are 16.4, 5.0, and 0.0 percent for the United States, Mexico, and India, respectively. If these fixed costs are interpreted as intangible investment, as Midrigan and Xu (2014) did, then the number for the United States is close to the 15.7 percent reported by Corrado, Hulten, and Sichel (2009) for the U.S. Non-Farm Business sector in 2000-2003. Estimates on intangible investment in India and
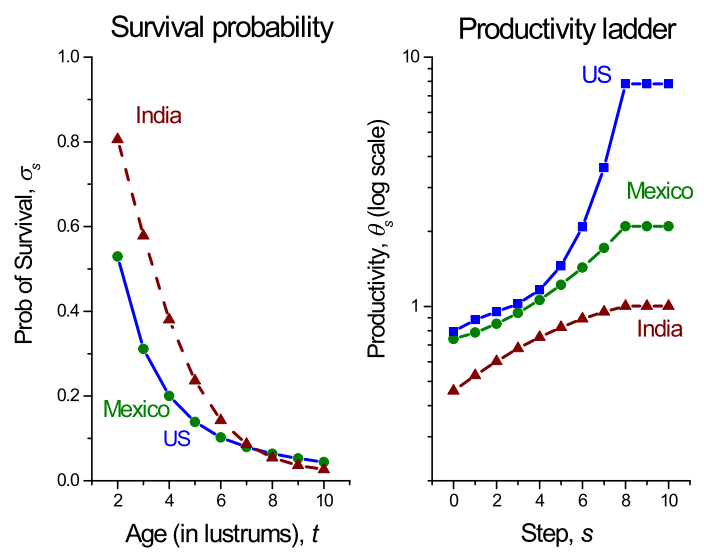

FIGURE 5.-Productivity and survival in India, Mexico, and the United States (model). The diagram displays the estimated productivity ladders (right panel) for India, Mexico, and the United States. It also illustrates the fitted probability profiles for survival (left panel). Age is measured in lustrums (or five year intervals). 
Mexico are not readily available, but Midrigan and Xu (2014) presented a number of 4.6 percent for South Korea, which is not too far from the 5.0 percent estimated for Mexico here.

\subsubsection{Establishment Size Distributions}

The model matches the U.S. establishment-size distribution very well, as seen in Figure 6, which plots this distribution in Lorenz-curve form. However, the model overpredicts the share of small establishments in employment. Mexican plants are about half ( 55 percent) the size of U.S. plants. They are also much smaller in the model, but it overpredicts somewhat their size (67 versus 55 percent), as shown in Table III. Plants in India are even smaller, about 11 percent of the size of American plants; the model predicts 14 percent.

Figure 7 plots the model's fit for the complementary cumulative distributions of employment by age for the three countries; that is, it graphs one minus the cumulative distribution of employment by age. ${ }^{18}$ Establishments older than 30 years account for a smaller fraction of employment in India or Mexico relative to the United States, as the right sides of the graphs show. The calibrated framework mimics the share of employment by age for Indian firms (the top panel) well. The size of old Indian plants in the model is too small (right side), though, and the model underpredicts the share of young plants in employment

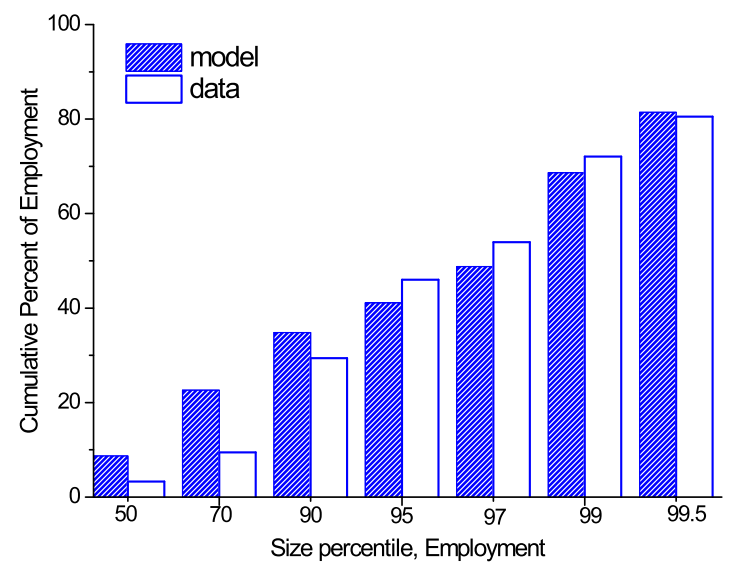

FIGURE 6.-U.S. establishment-size distribution in Lorenz-curve form: data and model. Data sources for all figures are presented in the Data Appendix (Supplemental Material).

\footnotetext{
${ }^{18}$ The data on establishments in India are problematic for at least two reasons. First, India has a large informal sector. Therefore, using statistics containing information about only the formal sector might be misleading. Second, the large differences between sectors in India-mainly agriculture versus manufacturing - imply that statistics computed at the aggregate level may not be close to those computed for manufacturing alone.
} 
TABLE III

STYLIZED FACTS, DATA VERSUS MODEL ${ }^{\mathrm{a}}$

\begin{tabular}{|c|c|c|c|c|c|c|}
\hline \multirow[b]{2}{*}{ Statistics } & \multicolumn{2}{|c|}{ U.S. } & \multicolumn{2}{|c|}{ Mexico } & \multicolumn{2}{|c|}{ India } \\
\hline & Data & Model & Data & Model & Data & Model \\
\hline Output per worker & 1.00 & 1.00 & 0.33 & 0.31 & 0.12 & 0.15 \\
\hline TFP & 1.00 & 1.00 & 0.46 & 0.40 & 0.24 & 0.25 \\
\hline Average firm size & 1.00 & 1.00 & 0.55 & 0.67 & 0.11 & 0.14 \\
\hline Debt-to-output ratio & 1.65 & 1.83 & 0.24 & 0.08 & 0.24 & 0.08 \\
\hline Employment share, age $\leq 10 \mathrm{yr}$ & 0.25 & 0.21 & 0.52 & 0.49 & 0.51 & 0.44 \\
\hline $\ln \left(\mathrm{TFP}_{\mathrm{age}>35}\right)-\ln \left(\mathrm{TFP}_{\mathrm{age}<5}\right)$ & 2.23 & 2.10 & 0.51 & 0.33 & 0.30 & 0.16 \\
\hline
\end{tabular}

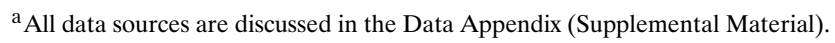

(left side). Next, consider Mexico (the middle panel). The fit here is excellent. Now switch to the United States (the bottom panel). The model does a good job matching the share of employment by age for the United States. Still, it does not quite capture the fact that some old firms in the United States are very large. Finally, note from Table III that the model's predictions about the relationship between employment and establishment age are captured using TFP profiles for plants that grow at roughly the correct rates for India, Mexico, and the United States. That is, employment grows with age faster in an American plant than in an Indian one because TFP grows faster in a plant in the United States compared with one in India.

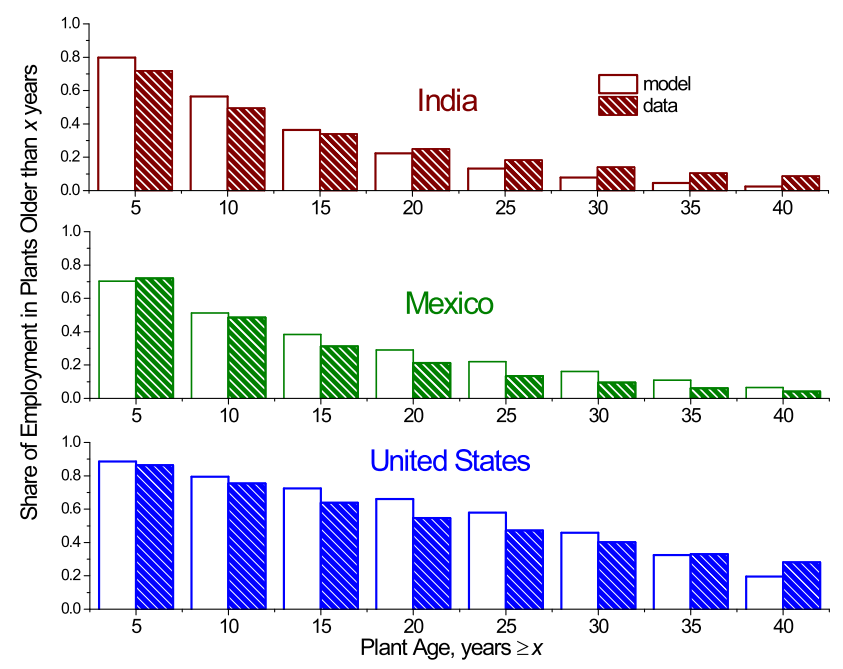

FIGURE 7.-The (complementary) cumulative distributions of employment by age $(\geq)$ for plants in India, Mexico, and the United States, data and model. 


\subsubsection{Productivity}

Can the above framework generate sizable differences in productivity between India, Mexico, and the United States, due to differences in technology adoption, which are in turn induced by differences in financial systems? Before proceeding, some definitions are needed. Aggregate output in a country is given by

$$
\mathbf{o}(\tau)=\sum_{t=1}^{T} \sum_{s=1}^{\min \{t, S\}} o(s, t ; \tau) \operatorname{Pr}(s, t ; \tau),
$$

where $o(s, t ; \tau)$ represents a firm's production at node $(s, t)$ when it uses the $\tau$ technology. Note that the odds of arriving at node $(s, t)$ are now also a function of $\tau$. In a similar vein, define the aggregate amounts of labor and physical capital that are hired by

$$
\begin{aligned}
& \mathbf{l}(\tau)=\sum_{t=1}^{T} \sum_{s=1}^{\min \{t, S\}} l(s, t ; \tau) \operatorname{Pr}(s, t ; \tau), \\
& \mathbf{k}(\tau)=\sum_{t=1}^{T} \sum_{s=1}^{\min \{t, S\}} \widetilde{k}(s, t ; \tau) \operatorname{Pr}(s, t ; \tau),
\end{aligned}
$$

where $l(s, t ; \tau)$ and $\tilde{k}(s, t ; \tau)$, respectively, denote the quantities of labor and physical capital that a firm will hire at node $(s, t)$ when it uses the $\tau$ technology.

Labor productivity in a country reads $\mathbf{o}(\tau) / \mathbf{l}(\tau)$. As can be seen, the model performs well in replicating the fact that productivity in Mexico is only onethird of productivity in the United States. Indian productivity is only one-tenth of the American level. The model duplicates this as well. Likewise, a measure of TFP can be constructed. In particular, TFP is defined as $\mathbf{o}(\tau) /\left[\mathbf{k}(\tau)^{\kappa} \mathbf{I}(\tau)^{1-\kappa}\right]$, where $\kappa$ is capital's share of income and is set to $1 / 3$. Indian and Mexican TFPs are 46 and 24 percent, respectively, of the U.S. level. The model replicates these facts well (40 and 25 percent).

\section{WHY DOESN'T TECHNOLOGY FLOW FROM RICH TO POOR COUNTRIES?}

What determines the technology a nation will use? Can differences in cashflow control and monitoring justify the adoption of less productive technologies in some countries, even when input prices are substantially less expensive (implying that the advanced technology will be very profitable in the absence of any contracting frictions)? As it turns out, there is a wide range of values for $\psi$ and $z$ that are consistent with the United States adopting the advanced technology, Mexico the intermediate one, and India the entry-level technology. Some diagrams are developed next to show this. 
For technology $\tau$ to operate in a country with a financial system characterized by $(\psi, z)$ requires that ${ }^{19}$

$$
v(q ; \psi, z, \tau)-\varepsilon_{\tau}=0,
$$

and

$$
v(q ; \psi, z, t)-\varepsilon_{t} \leq 0 \quad \text { for } \quad t \neq \tau \text { and } \tau, t \in\{\mathrm{IN}, \mathrm{MX}, \mathrm{US}\} .
$$

Recall that $\varepsilon_{\tau}$ is the cost to an entrepreneur of running technology $\tau$. Equation (20) is the zero-profit condition for technology $\tau$, while equation (21) ensures that it is not profitable for an entrepreneur to deviate and operate one of the other two technologies. Focus on the choice between the advanced and intermediate technologies. If an equilibrium occurs where the advanced technology is operated, then condition (20) implicitly describes an equilibrium input price function defined by $v(q ; \psi, z$, US $)-\varepsilon_{\mathrm{US}}=0$. Write this relationship as $q^{\mathrm{US}}=Q(z ; \psi, \tau=\mathrm{US})$. Similarly, when the intermediate technology is adopted, the condition $v(q ; \psi, z, \mathrm{MX})-\varepsilon_{\mathrm{MX}}=0$ will specify an input price locus $q^{\mathrm{MX}}=Q(z ; \psi, \tau=\mathrm{MX})$. Figure 8 plots the two price schedules, which result from the simulation, as a function of monitoring efficiency, $z$, when $\psi=0.06$ (the value in Mexico and the United States). For either technology, as monitoring becomes more efficient investment will increase, which will drive up wages and hence $q$. The function $Q(z ; \psi, \tau=\mathrm{US})$ moves up faster with $z$

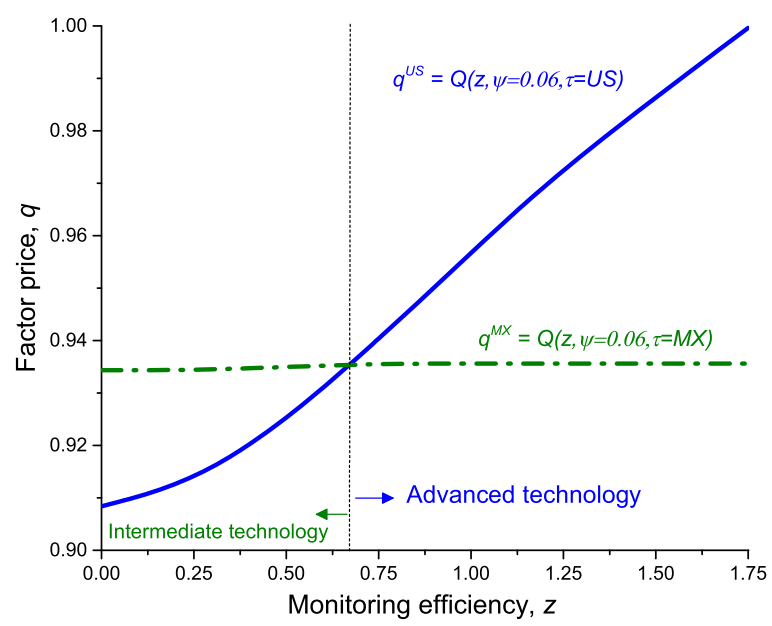

FIGURE 8.-The choice between the advanced and intermediate technologies as a function of monitoring efficiency, $z$.

${ }^{19}$ This condition for the simulated economy is the analog of (16). 
than the function $Q(z ; \psi, \tau=\mathrm{MX})$ because the advanced technology responds more to shifts in the efficiency of monitoring, $z$, than does the intermediate one.

Now focus on the points to the right of the vertical line in Figure 8. In this region, the advanced technology is adopted so equilibrium input prices will lie on the solid line. It is not profitable for an entrepreneur to deviate and operate the intermediate technology. To see why, note that along the lower dashed line, an entrepreneur would earn zero profits from operating the intermediate technology. Thus, at higher input prices, he would incur a loss. Suppose, counterfactually, that the intermediate technology is adopted in equilibrium; then input prices would be on the dashed line. Here, an entrepreneur should deviate and run the advanced technology. This occurs because along the higher solid line, the entrepreneur earns zero profits from the advanced technology. So, clearly, he would earn positive profits at the lower input prices on the dashed line. Therefore, an equilibrium where the intermediate technology is operated is not deviation proof. Observe the wide range of $z$ 's that are consistent with adopting either technology.

Figure 9 shows the adoption zones in $(\psi, z)$ space for each technology. That is, it illustrates the combinations of $\psi$ and $z$ that are consistent with the adoption of each technology. ${ }^{20}$ The diagram takes into account that as $\psi$ and $z$ change, so does $q$. In other words, it is done in general equilibrium. Focus on the boundary between the advanced and intermediate technologies, shown in the left panel of the figure. This "zooming in" spotlights Mexico and the United States. There is a trade-off between $\psi$ and $z$. Higher levels for $\psi$, which imply poorer cash-flow control, can be compensated for by higher values of $z$ or by greater efficiency in monitoring, at least up to a point. The points labeled "Mexico" and "USA" indicate the values for $\psi$ and $z$ that are used for these two countries in the simulation. At these two points, the cost of the amalgamated input, $q$, is the same as in the data for Mexico and the United States, that is, 0.94 and 1.0 .

The right panel of Figure 9 portrays the boundary between the entry-level and intermediate technologies. Again, there is a trade-off between $\psi$ and $z$ but now it is not as steep because monitoring is less important for these technologies. The point labeled "India" indicates the values for $\psi$ and $z$ for this country in the simulation. At this point, the price for the amalgamated input is 0.6 , the

\footnotetext{
${ }^{20}$ The retention parameter, $\psi$, has a natural interpretation. It represents the fraction of output that the firm can always keep, unless it is caught red-handed cheating, notwithstanding any action the intermediary takes. So, in India the firm can always keep 48 percent of output. This parameter has a similar interpretation to $1-\phi$ in Buera, Kaboski, and Shin (2011), which represents the fraction of undepreciated capital and output net of labor payments that an entrepreneur can keep if he reneges on his financial contract. It can be calculated that the value needed for $1-\phi$ in Buera, Kaboski, and Shin (2011) so that their model would match the Indian external debtto-GDP ratio is 0.88 . This corresponds to $\psi=0.57$ in the current setting, a magnitude similar to that used here. A discussion of the monitoring parameter, $z$, is deferred to Section 10.1.
} 

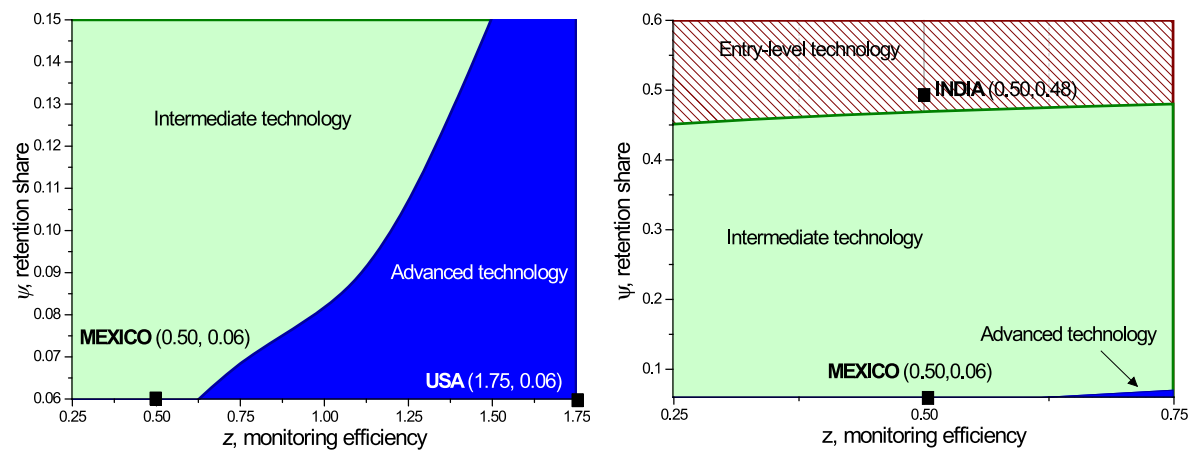

FIGURE 9.-Adoption zones in general equilibrium for the advanced, intermediate, and entry-level technologies as a function of $\psi$ and $z$.

value observed in India. The retention problem in India is so severe that it is far removed from being able to adopt the advanced technology. Last, note that each technology has large adoption zones. Thus, there are many combinations of $\psi$ and $z$ that are consistent with the adoption of a particular technology. In this sense, the analysis is quite robust.

Finally, by how much would the fixed cost, $\phi$, for the advanced technology need to be lowered so that India and Mexico would adopt it, holding fixed their price for the amalgamated input? India would adopt the advanced technology at 77 percent of the U.S. fixed cost value and Mexico at 88 percent. Note that because the price of the amalgamated input is lower in India and Mexico, firms in these countries would produce more output than in the United States. Thus, the fixed-cost-to-output ratio in India is 43.4 percent of the U.S. one, while for Mexico it is 84.9. If $q$ is allowed to change, then the fixed cost in each country would need to be lowered further to entice adoption. This experiment shows that the fixed costs would need to be lowered considerably to switch the pattern of adoption.

\subsection{The Role of Monitoring}

The average odds of being monitored by state, $s$, or $\left[\sum_{t>s} \operatorname{Pr}(s, t) p(s, t)\right] /$ $\sum_{t \geq s} \operatorname{Pr}(s, t)$, are illustrated in the left panel of Figure 10. As can be seen, for the U.S. technology the odds of being monitored after declaring a stall rise steeply toward the top of the ladder. The U.S. technology ladder is very convex, so the payoffs from lying are greatest at the last steps. At step $s=7$, the average monitoring probability (across all $t \geq 7$ ) exceeds 25 percent. Monitoring is also done for the Indian ladder, but for a different reason. Monitoring helps with the cash-flow control problem. With monitoring, someone who lies is more likely to be caught. They can then no longer retain part of the firm's cash flow. 


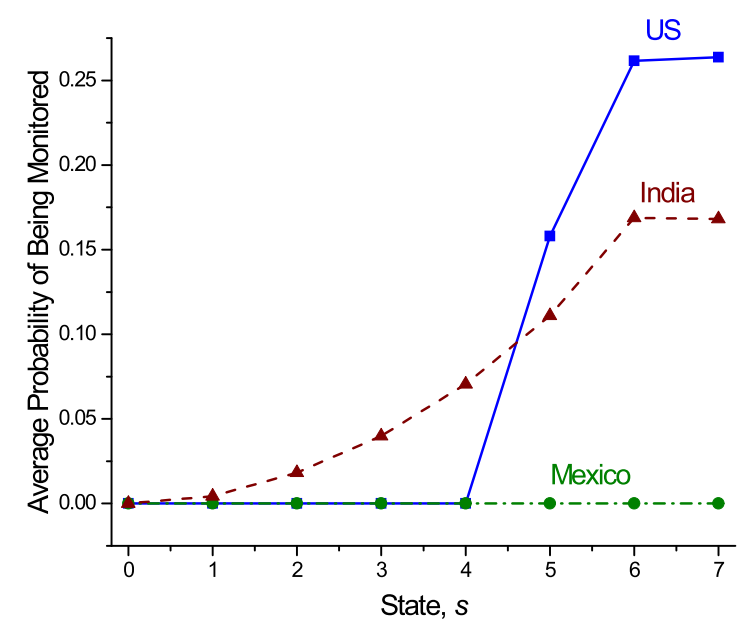

FIGURE 10.-The average monitoring probability in each state.

Very little monitoring is done for the Mexican ladder because monitoring is inefficient and expensive and the cash-flow control problem is small.

Imagine a contract with terms $\{k(s, t), x(s, t), p(s, t), \widetilde{f}\}_{t=1, s=0}^{T, \min \{t, S\}}$. How does the cost of monitoring for this contract in India compare with the United States? It is easy to deduce from (4) that the relative expected discounted cost of monitoring over the life of the contract is simply given by

$$
\begin{gathered}
\frac{\sum_{t=1}^{T} \sum_{s=0}^{\min \{t, S\}} \beta^{t} C\left(p(s, t), k(s, t) ; q^{\mathrm{IN}}, z^{\mathrm{IN}}\right) \operatorname{Pr}(s, t)}{\sum_{t=1}^{T} \sum_{s=0}^{\min \{t, S\}} \beta^{t} C\left(p(s, t), k(s, t) ; q^{\mathrm{US}}, z^{\mathrm{US}}\right) \operatorname{Pr}(s, t)} \\
=\frac{C\left(p, k ; q^{\mathrm{IN}}, z^{\mathrm{IN}}\right)}{C\left(p, k ; q^{\mathrm{US}}, z^{\mathrm{US}}\right)}=\frac{q^{\mathrm{IN}}}{q^{\mathrm{US}}}\left(\frac{z^{\mathrm{US}}}{z^{\mathrm{IN}}}\right)^{2}=7.4 .
\end{gathered}
$$

Thus, monitoring for a given contract is much more expensive in India than in the United States, due to the low level of $z$. The monitoring-cost-to-GDP ratio is much higher in the United States compared with India-specifically, 2.6 versus 0.01 percent. Why? The contracts are not the same. Note that the cost of monitoring rises convexly in $k / z$ and $p$. Firms are much larger in the United States (implying a higher $k / z$ ratio) than in India and monitoring in the United States increases sharply toward the end of the productivity ladder. 


\section{THE ROLE OF RETAINED EARNINGS IN FINANCING INVESTMENT}

\footnotetext{
"The entrepreneur does not save in order to obtain the means which he needs, nor does he accumulate any goods before he begins to produce."

"The entrepreneur is never the risk bearer.... The one who gives credit comes to grief if the undertaking fails.” Joseph A. Schumpeter (1961, pp. 136 and 137).
}

Two questions of interest are addressed here: (i) How does the entrepreneur's stake in the firm evolve over time? (ii) How much of the cost of capital is financed by the entrepreneur's share of cash flow? That is, how much capital expenditure is financed internally? To answer these two questions, objects from the dynamic contract must be translated into objects from accounting. Start with the notion of retained earnings. At any step/date pair $(s, t)$, the value of the firm to the entrepreneur, $v(s, t)$, is given by

$$
\begin{aligned}
& v(s, t) \\
& =\sum_{\tilde{t}=t}^{T} \sum_{\widetilde{s}=s}^{\min \{\tilde{t}, S\}} \beta^{\tilde{t}-t}\left[\theta_{\widetilde{s}} k(\widetilde{s}, \widetilde{t})^{\alpha}-x(\widetilde{s}, \widetilde{t})\right] \operatorname{Pr}(\widetilde{s}, \tilde{t}) / \operatorname{Pr}(s, t) \quad(\mathrm{cf} .(\mathrm{P} 2)) .
\end{aligned}
$$

This is just the expected present value of output net of the payments that the entrepreneur is obligated to make to the intermediary. In accounting parlance, $v(s, t)$ is the owner's equity or retained earnings at node $(s, t)$.

Next, what is the firm's debt at node $(s, t)$ ? To address this, the stream of payments $\{x(\widetilde{s}, \widetilde{t})\}$ is broken down into two mutually exclusive parts, a positive stream, $\{\max \{x(\widetilde{s}, \widetilde{t}), 0\}\}$, and a negative stream, $\{\min \{x(\widetilde{s}, \widetilde{t}), 0\}\}$. The firm's financial liability (which can be loosely thought of as debt) at $(s, t)$, or $d(s, t)$, coincides with the positive part and is given by

$$
d(s, t)=\sum_{\tilde{t}=t}^{T} \sum_{\tilde{s}=s}^{\min \{\tilde{t}, S\}} \beta^{\tilde{t}-t} \max \{x(\widetilde{s}, \tilde{t}), 0\} \operatorname{Pr}(\widetilde{s}, \tilde{t}) / \operatorname{Pr}(s, t)
$$

This financial liability is composed of two things. First, the firm must pay back the intermediary's loan. Second, the firm is surrendering some of its cash flow for contractual reasons that involve the creation of incentives. This part of the cash flow will be returned with interest at date $T$.

The payments that the intermediary will pay the firm in the future constitute a financial asset for the firm. The worth of this asset, $a(s, t)$, is given by

$$
a(s, t)=-\sum_{\tilde{t}=t}^{T} \sum_{\widetilde{s}=s}^{\min \{\tilde{t}, S\}} \beta^{\tilde{t}-t} \min \{x(\widetilde{s}, \tilde{t}), 0\} \operatorname{Pr}(\widetilde{s}, \tilde{t}) / \operatorname{Pr}(s, t) .
$$


TABLE IV

Translating Model ObJects Into Accounting Parlance

\begin{tabular}{lc}
\hline \hline & The Firm's Balance Sheet \\
\hline Assets & Liabilities and Retained Earning \\
\hline Present value of cash flow & Financial liabilities \\
$y(s, t)$ & $d(s, t)$ \\
Financial assets & Retained earnings (owner's equity) \\
$a(s, t)$ & $v(s, t)$ \\
\hline
\end{tabular}

The firm also owns the present value of its output, $y(s, t)$, which represents another asset:

$$
y(s, t) \equiv \sum_{\tilde{t}=t}^{T} \sum_{\tilde{s}=s}^{\min \{\tilde{t}, S\}} \beta^{\tilde{t}-t} \theta_{\tilde{s}} k(\widetilde{s}, \widetilde{t})^{\alpha} \operatorname{Pr}(\widetilde{s}, \widetilde{t}) / \operatorname{Pr}(s, t) .
$$

Now, it is easy to see that $y(s, t)+a(s, t)=d(s, t)+v(s, t)$. Putting everything together on a balance sheet gives Table IV. ${ }^{21}$

So, how does the entrepreneur's ownership of the firm evolve with its age or over time? The entrepreneur's share of the firm is given by $v(s, t) /[y(s, t)+$ $a(s, t)]$. At each point in time, take an average across states. The upshot is displayed in the left panel of Figure 11. As time progresses, the entrepreneur owns more of the firm in all three countries. There is not much investment associated with the entry-level technology. Therefore, in India an entrepreneur quickly owns most of his firm. By contrast, the advanced technology requires substantial investment, both in terms of the initial fixed cost and subsequent capital expenditures. Hence, an American entrepreneur's share of the firm increases more slowly; in fact, he never fully owns it. Not surprisingly, the curve for Mexico lies between the ones for India and the United States.

The evolution of the entrepreneur's stake in the firm will be reflected in the firm's debt. The importance of external finance in the literature is usually gauged by cross-country comparisons of measures of private credit to GDP. The private-credit-to-GDP ratio rises with GDP. This fact can be interpreted as indicating either that an entrepreneur's own start-up funds are more important in developing countries vis-à-vis developed ones or that internal finance is

\footnotetext{
${ }^{21}$ The firm's financial liability, $d(s, t)$, is an asset for the intermediary and will enter on the left side of the latter's balance sheet. The intermediary incurs a financial liability (dubbed a note payable) to supply the firm with working capital and to engage in monitoring, which enters on the right side of the intermediary's balance sheet. This liability, $n(s, t)$, reads $n(s, t)=$ $\sum_{\tilde{t}=t}^{T} \sum_{\widetilde{s}=s}^{\min \tilde{t}, S\}} \beta^{\tilde{t}-t}[q k(\widetilde{s}, \widetilde{t})+C(p(\widetilde{s}, \widetilde{t}), k(\widetilde{s}, \widetilde{t}))] \operatorname{Pr}(\widetilde{s}, \widetilde{t}) / \operatorname{Pr}(s, t)+I(t) \phi$, where $I(t)=1$, if $t=0$, and is zero otherwise. The contract contributes the amount $d(s, t)-n(s, t)$ to the intermediary's retained earnings (which is on the right side of the balance sheet).
} 

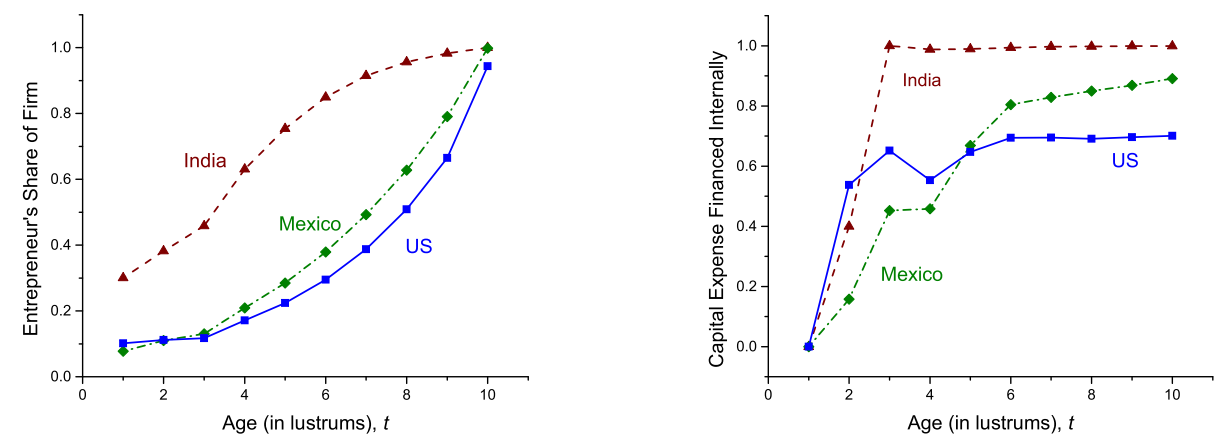

FIGURE 11.-The left panel shows how the share of the firm owned by the entrepreneur evolves with firm age. The right panel displays the fraction of the cost of physical capital that is financed by the firm.

more important in the former countries than the latter. Another interpretation is that developed countries use more advanced technologies than developing countries and that these technologies require more external funding than less advanced ones. What are the model's predictions for the private-debt-to-GDP ratios? These are presented in Table III. As can be seen, in the data the privatedebt-to-GDP ratio is much higher in the United States (1.65) than for either India (0.24) or Mexico (0.24). ${ }^{22}$ The model captures this fact in a qualitative sense $(1.83,0.08$, and 0.08$)$. It does reasonably well in matching the magnitudes for the United States, but it underpredicts the magnitudes for India and Mexico. Again, in the quantitative analysis, the entrepreneur's self-financed startup funds are set to zero $(f=0)$. This suggests that cross-country differences in the private-debt-to-GDP ratio may reflect differences in technology adoption. That is, more developed countries adopt more advanced technologies that, in turn, require higher levels of financing and hence debt. Selling drinks on the street requires smaller and less sustained levels of borrowing than launching rockets into space, so to speak.

How much of physical capital expenditure is financed by the entrepreneur's share of cash flow? The change in retained earnings across two consecutive periods reflects the portion of current cash flow that accrues to the firm. The change in retained earnings includes any realized capital gains/losses that occur when the firm transits across states and time and nets out payments to the

\footnotetext{
${ }^{22}$ Debt is constructed using the above formula for $d(s, t)$, but here $x(s, t)$ is replaced with $\widehat{x}(s, t)$, where $\widehat{x}(s, t)=x(s, t)-q k(s, t)$. That is, the firm is thought of as using its own cash flow to pay for its inputs instead of surrendering its cash flow to the intermediary and having the intermediary lend the money to buy its inputs. Clearly, this does not change the nature of the contract. It is easy to deduce that this does not change the value of retained earnings or the value of the firm's assets. Hence, the time pattern of the entrepreneur's stake in the firm remains the same.
} 
intermediary. The change in retained earnings, $\Delta e(s, t)$, is defined by

$$
\Delta e(s, t)= \begin{cases}v(s, t)-v(s-1, t-1), & \text { diagonal, } \\ v(s, t)-v(s, t-1), & \text { off diagonal. }\end{cases}
$$

The fraction of the cost of physical capital that is financed by (changes in) retained earnings (or that is financed internally) is

$$
i(s, t)= \begin{cases}\Delta e(s, t) /[r \tilde{k}(s+1, t+1)+\phi I(t)], & \text { diagonal, } \\ \Delta e(s, t) /[r \tilde{k}(s, t+1)], & \text { off diagonal, }\end{cases}
$$

where $r$ is the country-specific cost of capital and $I(t)=1$, if $t=0$, and $I(t)=0$, if $t>0$.

The right panel of Figure 11 plots the fraction of physical capital expenditure that is financed internally, where at each point in time an average across states is taken. For India, the fraction of physical capital expenditure that is financed internally rises rapidly early on. By contrast, the increase is much slower for the United States. This occurs for two reasons. First, the advanced technology has a much larger setup cost, which must be paid off to the intermediary. Second, the convex productivity profile implies that a lot of capital expenditure occurs toward the end of the project. In fact, the advanced technology always relies on some external finance.

\section{FINANCE AND DEVELOPMENT}

Imagine endowing India and Mexico with the U.S. financial system. Three questions come to mind: By how much would Mexican and Indian GDP increase? Would this bring them to the U.S. level of development? How much of the gain in output is due to the adoption of new technologies versus capital deepening? To address these questions, let $O\left(z, \psi ; r^{\mathrm{MX}}, \chi^{\mathrm{MX}}\right)$ represent the level of output that Mexico would produce if it had the financial system proxied for by $(z, \psi)$, given the Mexican rental rate on capital, $r^{\mathrm{MX}}$, and the Mexican level of human capital, $\chi^{\mathrm{MX}}$. The percentage gain in output from Mexico adopting the U.S. financial system is $100 \times$ $\left[\ln O\left(z^{\mathrm{US}}, \psi^{\mathrm{US}} ; r^{\mathrm{MX}}, \chi^{\mathrm{MX}}\right)-\ln O\left(z^{\mathrm{MX}}, \psi^{\mathrm{MX}} ; r^{\mathrm{MX}}, \chi^{\mathrm{MX}}\right)\right]$. The percentage of the gap in the difference between Mexican and U.S. output that would be closed is measured by $100 \times\left[\ln O\left(z^{\mathrm{US}}, \psi^{\mathrm{US}} ; r^{\mathrm{MX}}, \chi^{\mathrm{MX}}\right)-\ln O\left(z^{\mathrm{MX}}, \psi^{\mathrm{MX}} ; r^{\mathrm{MX}}, \chi^{\mathrm{MX}}\right)\right] /$ $\left[\ln O\left(z^{\mathrm{US}}, \psi^{\mathrm{US}} ; r^{\mathrm{US}}, \chi^{\mathrm{US}}\right)-\ln O\left(z^{\mathrm{Mx}}, \psi^{\mathrm{Mx}} ; r^{\mathrm{MX}}, \chi^{\mathrm{MX}}\right)\right]$. Similarly, let $T(z, \psi ;$ $\left.r^{\mathrm{MX}}, \chi^{\mathrm{MX}}\right)$ represent the level of TFP that Mexico would produce if it had the financial system $(z, \psi)$, again given $r^{\mathrm{MX}}$ and $\chi^{\mathrm{MX}}$. Here TFP is measured in the manner discussed earlier. By standard Solow accounting, the contribution of TFP growth to output growth, when Mexico adopts the U.S. financial system, is just $100 *\left[\ln T\left(z^{\mathrm{US}}, \psi^{\mathrm{US}} ; r^{\mathrm{MX}}, \chi^{\mathrm{MX}}\right)-\ln T\left(z^{\mathrm{MX}}, \psi^{\mathrm{MX}} ; r^{\mathrm{MX}}, \chi^{\mathrm{MX}}\right)\right] /$ $\left[\ln O\left(z^{\mathrm{US}}, \psi^{\mathrm{US}} ; r^{\mathrm{MX}}, \chi^{\mathrm{MX}}\right)-\ln O\left(z^{\mathrm{MX}}, \psi^{\mathrm{MX}} ; r^{\mathrm{MX}}, \chi^{\mathrm{MX}}\right)\right]$. Do the same thing for India. 
TABLE V

THE IMPACT FOR INDIA AND MEXICO OF ADOPTING THE U.S. FINANCIAL SYSTEM $\left(z=z^{\mathrm{US}}\right.$ AND $\left.\psi=\psi^{\mathrm{US}}\right)$

\begin{tabular}{lrcrcr}
\hline \hline & \multicolumn{3}{c}{ Mexico } & & \multicolumn{2}{c}{ India } \\
\cline { 2 - 3 } \cline { 5 - 6 } & Increase, \% & Gap Closed, \% & & Growth, \% & Gap Closed, \% \\
\hline Output per worker & 46.1 & 40.0 & & 71.8 & 38.4 \\
TFP & 42.8 & 52.9 & & 46.4 & 39.9 \\
Capital-to-labor ratio & 9.8 & 10.0 & & 76.3 & 36.0 \\
Debt-to-output ratio & 318.7 & 100.0 & 312.3 & 100.1 \\
& \multicolumn{3}{c}{ Decomposition of Output Growth, \% } \\
\cline { 2 - 5 } Contribution from TFP & \multicolumn{3}{c}{65} \\
Contribution from capital & \multicolumn{3}{c}{35} \\
\hline
\end{tabular}

Table V shows that both Mexico and India could increase their outputs considerably by adopting the U.S. financial system: 46.1 percent and 71.8 percent, respectively. These seemingly large numbers are in accord with the predictions from the quantitative models developed by Buera, Kaboski, and Shin (2011), Greenwood, Sanchez, and Wang (2013), and Townsend and Ueda (2010). Yet, adopting the U.S. financial system would close only 40.0 percent of the gap between Mexican and American incomes and 38.4 percent of the gap for India. This transpires because Mexico and India have lower levels of human capital than the United States and higher prices for physical capital. TFP would jump up by 42.8 percent in Mexico and by 46.4 percent in India. This is a consequence of adopting the U.S. technology.

Interestingly, the capital-to-labor ratio rises by only 9.8 percent in Mexico. In India, it moves up by 76.3 percent. The improvement in TFP accounts for 93 percent of Mexican output growth and 65 percent of Indian output growth. This is in line with King and Levine (1994), who reported that differences in productivities, and not factor supplies, are likely to explain differences in incomes across countries. The finding here is echoed in Midrigan and Xu (2014), who used a quantitative model and argued that the impact of financial frictions on economic development through the capital-deepening channel, versus a technology adoption one, is likely to be small. Last, the debt-to-output ratio increases by over 300 percent for both India and Mexico. When India and Mexico are endowed with the U.S. financial system, they adopt the advanced technology. From (20), it follows that the price of the amalgamated input in both of these countries is the same as in the United States; that is, $q^{\mathrm{IN}}=q^{\mathrm{MX}}=q^{\mathrm{US}}=1$. (This does not imply that wages are the same in the three countries because $r$ and $\chi$ are different.) Consequently, the same financial contract is offered to entrepreneurs in all three countries, resulting in equal levels of debt relative to output. 


\section{CONCLUSION}

The role of financial intermediation in underwriting business ventures is investigated here. The analysis stresses the interplay between the structure of technology and the ability of an intermediary to fund it. A dynamic costly state verification model of lending from intermediaries to firms is developed to examine this. The model is embedded into a general equilibrium framework where intermediation is competitive. A firm's level of productivity is private information. The framework has several unique features not found in the literature.

First, the costly state verification model presented has several novel characteristics. As in the conventional costly state verification paradigm, an intermediary is free to audit a firm's returns. The auditing technology imposed here, however, is quite flexible. Specifically, the intermediary can pick the odds of a successful audit. The costs of auditing are increasing and convex in this probability. Additionally, these costs are decreasing in the technological efficiency of the financial system. Also, it may not be possible to write a contract that secures, when desired, all of a firm's cash flow. This leakage in cash flow limits the ability of intermediaries to create incentives for firms that increase the likelihood of a successful venture. The analysis allows new firms to supply some of their own funds to help venture start-up. The financial contract between the firm and the intermediary delimits the amount of self-financing that the firm can achieve over time using retained earnings.

Second, to stress the nexus between finance and the structure of technology, the latter is given a more general representation than is traditionally found in the finance and development literature. Differences in business opportunities are represented by variations in the stochastic processes governing firms' productivities. A stochastic process is characterized by a non-decreasing movement along a productivity ladder. The positions of the rungs on the ladder and the odds of moving up the ladder differ by the type of venture. A stall on the ladder is an absorbing state.

The form of the technology has implications for finance. Some ventures have exciting potential for profit, but intermediaries are required to provide large up-front investments of working capital and have to wait for prolonged periods of time before any potential returns are realized. For such investments, the ability of an intermediary to conduct ex post monitoring and to control cash flows is important for the viability of long-term lending contracts. Monitoring is important for detecting malfeasance. The more efficient the monitoring, the less incentive there will be for a firm to cheat on the financial contract. Likewise, the ability to secure cash flows in the contract is vital for creating incentives using backloading strategies that improve the odds of a successful venture. The upshot is that the set of desirable technologies within a country is a function of the state of the nation's financial system. Therefore, a country's income and TFP also depend on its financial system. 
The theory presented is illustrated using a quantitative example. In line with Hsieh and Klenow (2014), the example focuses on three countries, India, Mexico, and the United States. The framework is specialized to a situation where there are three technologies: an advanced technology, an intermediate one, and an entry-level one. A general equilibrium is constructed where, given the efficiency of a country's financial system, firms in the United States choose to adopt the advanced technology, those in Mexico pick the intermediate one, and firms in India select the entry-level technology. This is done while matching each country's input prices and establishment-size distributions, so the analysis has some discipline. In the example, financial development plays an important role in economic development. Both Mexico and India could increase their GDPs significantly by adopting the U.S. financial system, with the technology adoption channel playing a more important role than the capital accumulation channel. Financial development is important, but is not the sole driver of economic development.

The quantitative illustration is used to underscore some key features of the theory. Both the structure of available technologies and the efficiency of a country's financial system are important for determining which technologies will be adopted. Given the efficiency of a nation's financial system, it may not be possible to finance the adoption of certain technologies. This is highlighted here by plotting the adoption zones for technologies as a function of financial system parameters. In the illustration here, India and Mexico cannot adopt the advanced technology used in the United States. Second, the use of longterm contracts may be important for funding some technologies. In the example presented, the advanced technology cannot be supported in the United States using short-term contracts. ${ }^{23}$ Financing this technology requires a commitment by the intermediary to (potentially) monitor firms for a prolonged period of time. The structure of a technology also determines how quickly a firm's physical capital accumulation can be self-financed using the cash flowing into retained earnings. The entry-level technology, used in India, did not require much up-front investment and yielded a payoff quickly. This technology can be self-financed rapidly using retained earnings. By contrast, the advanced technology, employed in the United States, had a large start-up cost and a long maturation period. It relies on external finance for an extended period of time. The cross-country differences in technology adoption led to the United States having a higher debt-to-GDP ratio than India and Mexico, in addition to greater GDP and TFP.

\footnotetext{
${ }^{23}$ The efficiency gains from long- versus short-term contracts were analyzed in Cole, Greenwood, and Sanchez (2016a). It was demonstrated that the advanced technology cannot be put into effect in the United States using a short-term contract. This is because a short-term contract leaves too much money on the table.
} 


\section{REFERENCES}

Aghion, P., AND P. HowitT (1992): “A Model of Growth Through Creative Destruction,” Econometrica, 60 (2), 323-351. [1487]

Antunes, A., T. CAVAlCANTI, AND A. Villamil (2008): "The Effect of Financial Repression and Enforcement on Entrepreneurship and Economic Development," Journal of Monetary Economics, 55 (2), 278-297. [1479]

BANERJEE, A. V., AND E. DUflo (2005): "Growth Theory Through the Lens of Development Economics," in Handbook of Economic Growth, Vol. 1A, ed. by P. Aghion and S. N. Durlauf. Amsterdam: Elsevier, 473-552. [1481]

BARRO, R. J., AND J. W. LEE (2013): "A New Data Set of Educational Attainment in the World, 1950-2010," Journal of Development Economics, 104 (C), 184-198. [1502]

BuerA, F. J., J. P. KABOSKI, AND Y. SHIN (2011): "Finance and Development: A Tale of Two Sectors," American Economic Review, 101 (5), 1964-2002. [1479,1481,1482,1486,1504,1510,1517]

Bushman, R. M., J. D. Piotroski, AND A. J. SMith (2004): "What Determines Corporate Transparency," Journal of Accounting Research, 42 (2), 207-252. [1483]

CAstro, R., G. L. Clementi, And G. M. MacDonald (2004): "Investor Protection, Optimal Incentives, and Economic Growth," Quarterly Journal of Economics, 119 (3), 1131-1175. [1479]

Cole, H. L., J. Greenwood, AND J. M. SANChEZ (2016a): “Why Doesn't Technology Flow From Rich to Poor Countries?" Working Paper 594, Rochester Center for Economic Research. $[1491,1497,1499,1503,1504,1519]$

(2016b): "Supplement to 'Why Doesn't Technology Flow From Rich to Poor Countries?'," Econometrica Supplemental Material, 84, http://dx.doi.org/10.3982/ECTA11150. [1483]

Corrado, C., C. R. Hulten, AND D. E. Sichel (2009): "Intangible Capital and U.S. Economic Growth," Review of Income and Wealth, 55 (3), 661-685. [1505]

GREENwoOd, J., AND B. JovanOvic (1990): "Financial Development, Growth, and the Distribution of Income," Journal of Political Economy, 98 (5), 1076-1107. [1481]

GreEnwoOD, J., J. M. SANCHEZ, AND C. WANG (2010): "Financing Development: The Role of Information Costs," American Economic Review, 100 (4), 1875-1891. [1479,1481]

(2013): "Quantifying the Impact of Financial Development on Economic Development," Review of Economic Dynamics, 16 (1), 194-215. [1479,1481,1517]

Guner, N., G. VenturA, AND D. Y. XU (2008): "Macroeconomic Implications of SizeDependent Policies," Review of Economic Dynamics, 11 (4), 721-744. [1486,1501]

HopenHAYN, H. A., AND R. Rogerson (1993): "Job Turnover and Policy Evaluation: A General Equilibrium Analysis," Journal of Political Economy, 101 (5), 915-938. [1500]

HsIEH, C. T., AND P. J. KLENOW (2014): “The Life Cycle of Plants in India and Mexico,” Quarterly Journal of Economics, 129 (3), 1035-1084. [1479,1519]

KING, R. G., AND R. Levine (1994): "Capital Fundamentalism, Economic Development and Economic Growth," Carnegie-Rochester Conference Series on Public Policy, 40 (June), 259-292. [1517]

LEVINE, R. (2005): "Finance and Growth: Theory and Evidence," in Handbook of Economic Growth, Vol. 1A, ed. by P. Aghion and S. N. Durlauf. Amsterdam: Elsevier, 865-934. [1484]

LuCAS, R. E. JR. (1990): "Why Doesn't Capital Flow From Rich to Poor Countries?" American Economic Review, 80 (2), 92-96. [1477]

MARCET, A., AND R. MARIMON (1992): "Communication, Commitment, and Growth," Journal of Economic Theory, 58 (2), 219-249. [1482]

MidRIGAN, V., AND D. Y. XU (2014): "Finance and Misallocation: Evidence From Plant-Level Data," American Economic Review, 104 (2), 422-458. [1479,1481,1482,1505,1506,1517]

MolL, B. (2014): "Productivity Losses From Financial Frictions: Can Self-Financing Undo Capital Misallocation?" American Economic Review, 104 (10), 3186-3221. [1482]

SCHOELlmAN, T. (2012): "Education Quality and Development Accounting," Review of Economic Studies, 79 (1), 388-417. [1502]

SCHUMPETER, J. A. (1961): The Theory of Economic Development: An Inquiry Into Profits, Capital, Credit, Interest, and the Business Cycle. Cambridge, MA: Harvard University Press. [1513] 
SiEgAL, J. J. (1992): “The Real Rate of Interest From 1800-1990: A Study of the U.S. and the U.K.," Journal of Monetary Economics, 29 (2), 227-252. [1501]

TownsEnd, R. M. (1979): "Optimal Contracts and Competitive Markets With Costly State Verification," Journal of Economic Theory, 21 (2), 256-293. [1478]

TOWNSEND, R. M., AND K. UEDA (2010): "Welfare Gains From Financial Liberalization," International Economic Review, 51 (3), 553-597. [1479,1517]

WiLliamson, S. D. (1986): "Costly Monitoring, Financial Intermediation, and Equilibrium Credit Rationing," Journal of Monetary Economics, 18 (2), 159-179. [1478]

Dept. of Economics, University of Pennsylvania, Philadelphia, PA 19104-6297, U.S.A.; colehl@sas.upenn.edu,

Dept. of Economics, University of Pennsylvania, Philadelphia, PA 19104-6297, U.S.A.; non-cotees@jeremygreenwood.net,

and

Research Division, Federal Reserve Bank of St. Louis, P.O. Box 442, St. Louis, MO 63166-0442, U.S.A.; Juan.M.Sanchez@stls.frb.org.

Co-editor Lars Peter Hansen handled this manuscript.

Manuscript received October, 2012; final revision received February, 2016. 


\section{SUPPLEMENT TO “WHY DOESN'T TECHNOLOGY FLOW FROM RICH TO POOR COUNTRIES?"}

(Econometrica, Vol. 84, No. 4, July 2016, 1477-1521)

\section{By HAROld L. COLE, JeREMy GREENWOOd, AND JUAN M. SANCHEZ}

THIS SUPPLEMENT CONTAINS TWO APPENDICES, namely, Appendix A and B. Appendix A deals with theoretical aspects of the analysis. In particular, it provides the proofs for all of the lemmas in the paper. Appendix B pertains to the empirical work and discusses the data used.

\section{APPENDIX A: THEORY}

\section{A.1. Proofs for the Contract Problem (P2)}

Some lemmas and proofs describing the structure of the optimal contract are now presented. All lemmas and proofs apply to the appended version of problem (P2), where the no-retention constraints (12) and (13) have been added.

\section{A.2. Proof of Go All In}

ProOF OF LEMMA 1: Let $\lambda$ be the multiplier associated with the zero-profit constraint (10) and $\xi$ be the multiplier connected with the self-financing constraint (11). The first-order condition linked with $\widetilde{f}$ is

$$
-1+\lambda-\xi=0 .
$$

If $\xi>0$, then the constraint (11) is binding, and the result holds automatically. Alternatively, if $\xi=0$, then $\lambda=1$. In this situation, the firm is indifferent between investing in its own project or placing the funds in a bank. On the one hand, by giving $\widetilde{f}$ to the intermediary the firm lowers its payoff in the objective function by $\widetilde{f}$. On the other hand, this is exactly compensated for by loosening the zero-profit constraint that will result in a decrease in the payments from the firm to the intermediary (or the $x(s, t)$ 's) in the capitalized amount $\widetilde{f}$. Q.E.D.

REMARK 1: Since $\lambda=1+\xi$ and $\xi \geq 0$, it must transpire that $\lambda \geq 1$. This makes intuitive sense. When the entrepreneur hands over wealth to the intermediary, the lowest expected gross return that he can receive is $1 / \beta$. This is what a saver earns from depositing funds with the intermediary. This is worth exactly 1 in present-value terms. 


\section{A.3. Transformation of Problem (P2) With Self-Financing to Problem (P5) Without It}

Lemma 1 allows problem (P2) with self-financing to be converted into an equivalent problem (P5) without self-financing. The latter problem has a smaller value for the fixed costs, $\widehat{\phi}$; specifically, $\widehat{\phi}=\phi-f$ :

$$
v=\max _{\{k(s, t), x(s, t), p(s, t)\}} \sum_{t=1}^{T} \sum_{s=0}^{\min \{t, S\}} \beta^{t}\left[\theta_{s} k(s, t)^{\alpha}-x(s, t)\right] \operatorname{Pr}(s, t),
$$

subject to (6) to (9), the new zero-profit constraint (22), and the no-retention constraints (12) and (13). Note that the self-financing constraint (11) has now been eliminated:

$$
\begin{aligned}
\sum_{t=1}^{T} & \sum_{s=0}^{\min \{t, S\}} \beta^{t}[x(s, t)-C(p(s, t), k(s, t))-q k(s, t)] \operatorname{Pr}(s, t) \\
& -\underbrace{(\phi-f)}_{\widehat{\phi}} \geq 0 .
\end{aligned}
$$

Lemma 6-Conversion of Problem With Self-Financing to One Without Self-Financing: The problem with self-financed start-up funds $(\mathrm{P} 2)$ reduces to problem (P5), where the fixed cost is $\widehat{\phi}=\phi-f$.

Proof: Focus on problem (P2). In line with Lemma 1, set $\tilde{f}=f$. Use this fact to eliminate $f-\tilde{f}$ in the objective function and to replace $\tilde{f}$ with $f$ in the zero-profit condition.

Q.E.D.

REMARK 2: All that matters for the contract is $\phi-f$, given the above lemma. That is, what matters for the contract is the amount of initial funds that the intermediary must put up, and this is consistent with many different combinations of $\phi$ and $f$. Thus, a project with a fixed cost of $\phi$, where the entrepreneur has $f$ in start-up funding, will have the same allocations as one where the fixed cost is $\phi-f$, but where the entrepreneur has no start-up funds. Therefore, without cross-country data on $\phi$ and $f$ separately, it may be difficult to ascertain how much start-up funds matter.

In what follows, the proofs in Sections A.4, A.5, and A.6 refer to the transformed problem (P5).

\section{A.4. Proof of Trust but Verify}

PROOF OF LEMMA 2: (Necessity) It will be shown that the intermediary will monitor the firm at node $(u-1, t)$ (for all $t \geq u$ ) only if the incentive constraint 
(7) binds at $(u, u)$. Assume otherwise; that is, suppose to the contrary that the incentive constraint does not bind at $(u, u)$ but that $p(u-1, t)>0$ for some $t \geq u$. The term $p(u-1, t)$ shows up in only two equations in the appended version of problem (P5): in the zero-profit constraint of the intermediary (22) and on the right-hand side of the incentive constraint $(7)$ at node $(u, u)$. Picture the Lagrangian associated with problem (P5). By setting $p(u-1, t)=0$, profits to the intermediary can be increased through the zero-profit constraint (22). This raises the value of the Lagrangian. At the same time, it will have no impact on the maximum problem through the incentive constraint (7) because its multiplier is zero. Therefore, the value of the Lagrangian can be raised, a contradiction.

(Sufficiency) Assume that the incentive constraint (7) binds at $(u, u)$ and that $p(u-1, t)=0$ for some $t \geq u$. Note that the marginal cost of monitoring is zero at node $(u-1, t)$ since $C_{1}(0, k(u-1, t))=0$. Now increase $p(u-1, t)$ slightly. This relaxes the incentive constraint and thereby increases the value of the Lagrangian. It has no impact on the zero-profit condition (22) as $C_{1}(0, k(u-1, t))=0$. This implies a contradiction because the value of the Lagrangian will increase.

Q.E.D.

\section{A.5. Proof of Backloading: Lemmas 3 and 4}

Proof of LemMa 4, WITH Lemma 3 AS A SPECIAL CASE: Consider the no-retention constraint (12) at node $(s, s+1)$. Here a stall has just occurred. To satisfy the no-retention constraint at this point, the present value of the payments to the firm from there onward must be at least as large as $\psi \sum_{t=s+1}^{T} \beta^{t} \theta_{s} k(s, t)^{\alpha} \operatorname{Pr}(s, j)$. This is what the firm can take by exercising its retention option. This payment, which is necessary, should be made at node $(s, T)$. Thus, at node $(s, T)$, pay the amount $N(s, T)=$ $\psi \sum_{t=s+1}^{T} \beta^{t} \theta_{s} k(s, t)^{\alpha} \operatorname{Pr}(s, j) /\left[\beta^{T} \operatorname{Pr}(s, T)\right]$. Shifting the retention payments along the path $(s, s+1),(s, s+2), \ldots,(s, T-1)$ to the node $(s, T)$, by increasing $x(s, s+1), x(s, s+2), \ldots, x(s, T-1)$ and lowering $x(s, T)$, helps with incentives. It reduces the right-hand side of the incentive constraint (7) at node $(s+1, s+1)$. This occurs because the firm will not receive the retention payment if it is caught lying at some node $(s, s+j)$ for $j>1$. It has no impact on the right-hand side at other nodes along the technology ladder's diagonal. This shift does not affect the left-hand side of (7). Moreover, if the payments are set according to point (2) in the lemma, it follows by construction that the no-retention constraint (12) holds at all nodes $(s, t)$, for $t \geq s+1$. It is not beneficial to pay a retention payment bigger than $N(s, T)=\psi \sum_{t=s+1}^{T} \beta^{t} \theta_{s} k(s, t)^{\alpha} \operatorname{Pr}(s, j) /\left[\beta^{T} \operatorname{Pr}(s, T)\right]$, as will be discussed.

Suppose that $x(s, t)<\theta_{s} k(s, t)^{\alpha}$ at some node $(s, t)$, for $s \leq t<T$. It will be established that, by setting $x(s, t)=\theta_{s} k(s, t)^{\alpha}$, the incentive constraint (7) can be (weakly) relaxed. Suppose $t=s$. Then, increase $x(s, s)$ by $\theta_{s} k(s, s)^{\alpha}-$ 
$x(s, s)$ and reduce $x(S, T)$ by $\left[\theta_{s} k(s, s)^{\alpha}-x(s, s)\right]\left[\beta^{s-T} \operatorname{Pr}(s, s) / \operatorname{Pr}(S, T)\right]$. In other words, shift the payment to the firm from node $(s, s)$ to node $(S, T)$ while keeping its present value constant. The left-hand sides of the incentive constraints (7), for $u \leq s$, will remain unchanged. For $u>s$, the left-hand sides will increase. The right-hand sides of the incentive constraints will remain constant, however. Thus, this change will help relax any binding incentive constraints. This shift also helps with the no-retention constraints (13) for $u>s$. Next, suppose that $s<t<T$. Presume that a retention payment is made at $(s, T)$ in the amount $N(s, T)$, as specified by (14). As discussed above, a payment of at least this size must be made at node $(s, T)$ to prevent retention at node $(s, s+1)$. It will be argued below that it is not beneficial to pay a higher amount. For the off-diagonal node $(s, t)$, raise $x(s, t)$ by $\theta_{s} k(s, t)^{\alpha}-x(s, t)$ and reduce $x(S, T)$ by $\left[\theta_{s} k(s, s)^{\alpha}-x(s, t)\right]\left[\beta^{t-T} \operatorname{Pr}(s, t) / \operatorname{Pr}(S, T)\right]$. This change can only increase the left-hand side of the incentive constraints for $u>s$ and has no impact elsewhere. It reduces the right-hand side at node $(s, s)$. The right-hand sides elsewhere are unaffected. This change also helps with the no-retention constraints (13) for $u>s$. Finally, consider the node $(s, T)$, for $s<S$. A similar line of argument can be employed to show that it is not optimal to set $x(s, T)<\theta_{s} k(s, T)^{\alpha}-N(s, T)$, that is, to pay a retention payment bigger than $N(s, T)$.

Q.E.D.

COROLlary 1-Lemma 3: If $\psi=0$, then $x(s, T)=0$; that is, it is weakly efficient to take all of a firm's output at every node but $(S, T)$. Thus, Lemma 3 is a special case of Lemma 4.

\section{A.6. Proof of Efficient Investment}

PROOF OF LEMMA 5: The first step is to define the first-best allocation. The first-best allocation for working capital solves the following time-0 problem:

$$
\max _{\{k(s, t)\}}\left\{\sum_{t=1}^{T} \sum_{s=0}^{\min \{t, S\}} \beta^{t}\left[\theta_{s} k(s, t)^{\alpha}-q k(s, t)\right] \operatorname{Pr}(s, t)\right\}-\phi,
$$

subject to the information and irreversibility constraints, (8) and (9). Now, $k(s, t)=k(s, s+1)=k(s+1, s+1)$ for all $t>s$, by the information and irreversibility constraints. This allows the above problem to be recast as

$$
\begin{aligned}
& \max _{\{k(s, s+1)\}}\left\{\sum_{t=1}^{T} \beta^{t} \sum_{s=0}^{\min \{t-1, S\}}\left[\theta_{s} k(s, s+1)^{\alpha}-q k(s, s+1)\right] \operatorname{Pr}(s, t)\right. \\
& \left.+\sum_{s=0}^{S-1} \beta^{s+1}\left[\theta_{s+1} k(s, s+1)^{\alpha}-q k(s, s+1)\right] \operatorname{Pr}(s+1, s+1)\right\}-\phi .
\end{aligned}
$$


Focus on some $k(s, s+1)$. It will show up in the top line of the objective function whenever $t \geq s+1$. It appears once in the second line. The first-order condition for $k(s, s+1)$ is

$$
\begin{aligned}
& \sum_{t=s+1}^{T} \beta^{t}\left[\alpha \theta_{s} k(s, s+1)^{\alpha-1}-q\right] \operatorname{Pr}(s, t) \\
& \quad+\beta^{s+1}\left[\alpha \theta_{s+1} k(s, s+1)^{\alpha-1}-q\right] \operatorname{Pr}(s+1, s+1)=0,
\end{aligned}
$$

for $s=0, \ldots, S-1$. A similar first-order condition holds for the top of the ladder.

For the second step, turn to the appended version of problem (P5). Now, using the information, irreversibility, and zero-profit constraints, (8), (9), and (22), in conjunction with the solution for the $x(s, t)$ 's presented in Lemma 4, the contracting problem can be rewritten as

$$
\begin{aligned}
& \max _{\{k(s, s+1), p(s, t)\}}\left\{\sum _ { t = 1 } ^ { T } \beta ^ { t } \sum _ { s = 0 } ^ { \operatorname { m i n } \{ t - 1 , S \} } \left[\theta_{s} k(s, s+1)^{\alpha}-C(p(s, t), k(s, s+1))\right.\right. \\
& -q k(s, s+1)] \operatorname{Pr}(s, t) \\
& +\sum_{s=0}^{S-1} \beta^{s+1}\left[\theta_{s+1} k(s, s+1)^{\alpha}-C(p(s+1, s+1), k(s, s+1))\right. \\
& -q k(s, s+1)] \operatorname{Pr}(s+1, s+1)\}-\phi,
\end{aligned}
$$

subject to the $2 S$ incentive and diagonal-node no-retention constraints:

$$
\begin{aligned}
& \sum_{t=u+1}^{T} \beta^{t} \sum_{s=u}^{\min \{t-1, S\}}\left[\theta_{s} k(s, s+1)^{\alpha}-C(p(s, t), k(s, s+1))\right. \\
& \quad-q k(s, s+1)] \operatorname{Pr}(s, t) \\
& \quad+\sum_{s=u-1}^{S-1} \beta^{s+1}\left[\theta_{s+1} k(s, s+1)^{\alpha}-C(p(s+1, s+1), k(s, s+1))\right. \\
& \quad-q k(s, s+1)] \operatorname{Pr}(s+1, s+1)-\phi \\
& \quad-\sum_{s=0}^{u-1} \psi \theta_{s} k(s, s+1)^{\alpha} \sum_{t=s+1}^{T} \beta^{t} \operatorname{Pr}(s, t)
\end{aligned}
$$




$$
\begin{aligned}
& \geq k(u-1, u)^{\alpha}\left\{\sum_{i=u}^{S}\left(\theta_{i}-\theta_{u-1}\right)\left\{\sum_{j=i}^{T} \beta^{j} \operatorname{Pr}(i, j) \prod_{n=u}^{j}[1-p(u-1, n)]\right\}\right. \\
& \left.\quad+\beta^{T} \operatorname{Pr}(i, T) \prod_{n=u}^{T}[1-p(u-1, n)]\left[\psi \frac{\sum_{t=u}^{S} \beta^{t} \operatorname{Pr}(u-1, t)}{\beta^{T} \operatorname{Pr}(u-1, T)}\right]\right\}
\end{aligned}
$$

and

$$
\begin{aligned}
\sum_{t=u+1}^{T} \beta^{t} & \sum_{s=u}^{\min \{t-1, S\}}\left[\theta_{s} k(s, s+1)^{\alpha}-C(p(s, t), k(s, s+1))\right. \\
& -q k(s, s+1)] \operatorname{Pr}(s, t) \\
& +\sum_{s=u-1}^{S-1} \beta^{s+1}\left[\theta_{s+1} k(s, s+1)^{\alpha}-C(p(s+1, s+1), k(s, s+1))\right. \\
& -q k(s, s+1)] \operatorname{Pr}(s+1, s+1)-\phi \\
& -\sum_{s=0}^{u-1} \psi \theta_{s} k(s, s+1)^{\alpha} \sum_{t=s+1}^{T} \beta^{t} \operatorname{Pr}(s, t) \\
\geq & \psi k(u-1, u)^{\alpha} \sum_{t=u}^{T} \sum_{s=u}^{\min \{t, S\}} \beta^{t} \theta_{s} \operatorname{Pr}(s, t),
\end{aligned}
$$

for $u=1, \ldots, S$. Let $\iota_{u}$ and $\nu_{u}$ represent the multipliers attached to the $u$ th incentive and diagonal-node no-retention constraints, respectively. Now suppose that, after some diagonal node $\left(t^{*}, t^{*}\right)$, neither the incentive nor diagonal-node no-retention constraints ever bind again; that is, let $\left(t^{*}, t^{*}\right)$ be the last diagonal node at which one or both of the incentive and no-retention constraints bind. Consider one of the incentive or no-retention constraints up to and including node $\left(t^{*}, t^{*}\right)$. The variable $k(s, s+1)$ will not show up on the right-hand side of any of these constraints. Examine the left-hand side. The variable $k(s, s+1)$ appears in the first line whenever $t \geq s+1$ and in the second line once. It does not appear in the third line because $s \leq u-1$. Therefore, the first-order condition for $k(s, s+1)$ is

$$
\begin{gathered}
{\left[1+\sum_{j=1}^{t^{*}}\left(\iota_{j}+\nu_{j}\right)\right]\left\{\sum_{t=s+1}^{T} \beta^{t}\left[\alpha \theta_{s} k(s, s+1)^{\alpha-1}-q\right] \operatorname{Pr}(s, t)\right.} \\
\left.+\beta^{s+1}\left[\alpha \theta_{s+1} k(s, s+1)^{\alpha-1}-q\right] \operatorname{Pr}(s+1, s+1)\right\}=0
\end{gathered}
$$


for $s \geq t^{*}$. Recall that $p(s, t)=0$ whenever the incentive constraint does not bind, by Lemma 2 , so that $C_{2}(0, k(s, s+1))=0$.

For the last step, divide the above first-order condition by $1+\sum_{j=1}^{t^{*}}\left(\iota_{j}+\nu_{j}\right)$. It now coincides with the one for the planner's problem. Thus, investment is efficient.

Q.E.D.

\section{APPENDIX B: DATA}

\section{B.1. Section 2}

The data used for real GDP and TFP are derived from Penn World Table 8. For each country, an average value for these series is calculated from 1995 on. The information variable is the FACTOR1 series presented in Bushman, Piotroski, and Smith (2004, Appendix B). Three series from the World Bank's Doing Business database are aggregated using factor analysis to obtain an index for the cost of enforcing contracts. The series are time (days), cost (\% of claims), and procedures (number). For each country, an average of these series is taken from 2003 on. Last, the series on financial development are taken from the World Bank's Global Financial Development data set. The series used for "findev" is "private credit by deposit money banks and other financial institutions to GDP (\%)." Here an average from 2005 on is taken. Three other series were also entered as the additional third variable in the regression: viz, firms identifying access to finance as a major constraint (\%), loans requiring collateral (\%), and the value of collateral needed for a loan (\% of the loan amount). These series had no predictive power in the regressions (albeit they reduced the sample size) and so are omitted from the reporting.

\section{B.2. Table 3}

Average Establishment Size. Data for average establishment size are from different sources for each country. (i) The number for India is based on information obtained from two sources: the Annual Survey of Industries (ASI) for 2007-2008, which gathers data on formal sector manufacturing plants, and the National Sample Survey Organization (NSSO) for 2005-2006, which collects data on informal sector manufacturing establishments. (ii) The figure for Mexico is calculated using data from Mexico's 2004 Economic Census conducted by INEGI. (iii) The number for the United States is derived from figures in the 2002 Economic Census published by the U.S. Census Bureau.

\section{B.3. Figure 6}

A special request was made to obtain these data. Data for the United States are from the 2002 Economic Census published by the U.S. Census Bureau. They can be obtained using the U.S. Census Bureau's FactFinder. 
TABLE B.I

UNITED STATES

\begin{tabular}{lrcrrr}
\hline \hline & \multicolumn{2}{c}{ Raw Data } & & \multicolumn{2}{c}{ Cumulative Share } \\
\cline { 2 - 3 } & \multicolumn{1}{c}{ Estab } & Empl & & Estab & Empl \\
\hline All establishments & 350,828 & $14,699,536$ & & \\
Establishment size & & & & \\
1 to 4 employees & 141,992 & 279,481 & & 40.5 & \\
5 to 9 & 49,284 & 334,459 & & 54.5 & 4.18 \\
10 to 19 & 50,824 & 702,428 & & 69.0 & 8.96 \\
20 to 49 & 51,660 & $1,615,349$ & & 83.7 & 19.94 \\
50 to 99 & 25,883 & $1,814,999$ & & 91.1 & 32.29 \\
100 to 249 & 20,346 & $3,133,384$ & & 96.9 & 53.61 \\
250 to 499 & 6,853 & $2,357,917$ & & 98.9 & 69.65 \\
500 to 999 & 2,720 & $1,835,386$ & & 99.6 & 82.13 \\
1,000 to 2,499 & 1,025 & $1,494,936$ & & 99.9 & 92.30 \\
2,500 or more & 241 & $1,131,197$ & & 100.0 & 100.00 \\
Mean establishment size & & 41.9 & & \\
\hline
\end{tabular}

\section{B.4. Figure 7}

The data for India, Mexico, and the United States displayed in Figure 7 are from Hsieh and Klenow (2014). Table B.II shows the statistics used to construct Figure 7.

TABLE B.II

HSIEH AND KLENOW (2014) FACTS

\begin{tabular}{lccc}
\hline \hline & \multicolumn{3}{c}{ Employment Share } \\
\cline { 2 - 4 } Establishment Age (yr) & U.S. (2002) & Mexico (2003) & India (1994) \\
\hline$<5$ & 0.137 & 0.280 & 0.282 \\
$5-9$ & 0.110 & 0.235 & 0.224 \\
$10-14$ & 0.115 & 0.173 & 0.155 \\
$15-19$ & 0.092 & 0.100 & 0.089 \\
$20-24$ & 0.074 & 0.077 & 0.067 \\
$25-29$ & 0.072 & 0.039 & 0.043 \\
$30-34$ & 0.072 & 0.035 & 0.036 \\
$35-39$ & 0.049 & 0.019 & 0.018 \\
$>39$ & 0.280 & 0.041 & 0.086 \\
\hline
\end{tabular}


Dept. of Economics, University of Pennsylvania, Philadelphia, PA 19104-6297, U.S.A.; colehl@sas.upenn.edu,

Dept. of Economics, University of Pennsylvania, Philadelphia, PA 19104-6297, U.S.A.; non-cotees@jeremygreenwood.net,

and

Research Division, Federal Reserve Bank of St. Louis, P.O. Box 442, St. Louis, MO 63166-0442, U.S.A.; Juan.M.Sanchez@stls.frb.org.

Co-editor Lars Hansen handled this manuscript.

Manuscript received October, 2012; final revision received February, 2016. 